\title{
Contrasting regional and global climate simulations over South Asia
}

\author{
Arun Rana ${ }^{1,2}{ }^{\mathbb{D}} \cdot$ Grigory Nikulin $^{1} \cdot$ Erik Kjellström $^{1,3} \cdot$ Gustav Strandberg $^{1} \cdot$ Marco Kupiainen $^{1} \cdot$ Ulf Hansson ${ }^{1}$. \\ Michael Kolax ${ }^{1}$
}

Received: 3 May 2019 / Accepted: 24 January 2020 / Published online: 31 January 2020

(c) The Author(s) 2020

\begin{abstract}
Two ensembles of climate simulations, one global and one regional, are used to investigate model errors and projected climate change in seasonal mean temperature and precipitation over South Asia. The global ensemble includes ten global climate models (GCMs). In the regional ensemble all ten GCMs are downscaled by a regional climate model—RCA4 over South Asia at $50 \mathrm{~km}$ resolution. Our focus is on the Indian Summer Monsoon season (June-August) and we show that RCA4 can reproduce, reduce or amplify large-scale GCM biases depending on regions and GCMs. However, the RCA4 bias pattern in precipitation is similar across the simulations, regardless of forcing GCM, indicating a strong RCA4 imprint on the simulated precipitation. For climate change, the results indicate, that RCA4 can change the signal projected by the GCM ensemble and its individual members. There are a few RCA4 simulations with a substantial reduction of projected warming by RCA4 compared to the driving GCMs and with a large regional increase in precipitation absent in the GCMs. We also found that in a number of subregions warm RCA4 biases are related to stronger warming and vice versa, while there is no such dependency in the GCM ensemble. Neither the GCM nor the RCA4 ensemble shows any significant dependency between projected changes and biases for precipitation. Our results implicate that using only RCMs and excluding GCMs, a commonly established approach, can significantly change the message on future regional climate change.
\end{abstract}

Keywords South Asia $\cdot$ Climate change $\cdot$ CORDEX $\cdot$ CMIP5

\section{Introduction}

South Asia is one of the most densely populated regions in the world and, at the same time, is particular vulnerable to impacts of climate change and variability (Hijioka et al. 2014). The region is strongly influenced by the Asian Monsoon in boreal summer and undergoes large interannual, decadal and multi-decadal variability, expressed as extremely wet/dry and/or relatively mild/hot conditions. India, the largest country in South Asia, with a population of more than 1.2 billion people strongly dependent on sectors

Arun Rana

arunranain@gmail.com

1 Swedish Meteorological and Hydrological Institute, Rossby Centre, 60176 Norrköping, Sweden

2 Université catholique de Louvain, Earth and Life Institute (ELIC), Place Louis Pasteur 3, 1348 Louvain-la-Neuve, Belgium

3 Department of Meteorology and the Bolin Centre for Climate Research, Stockholm University, 10691, Stockholm, Sweden sensitive to climate conditions notably influencing agriculture and infrastructure.

A warming trend of about $0.5{ }^{\circ} \mathrm{C}$ has been observed in India over the last century with accelerated warming observed since the 1970s (Kothawale et al. 2010). The number of hot events/heat waves is also increasing (Revadekar et al. 2012; Pai et al. 2013; Mishra et al. 2015). Most of India receives much of its annual amount of rainfall in boreal summer from the Indian Summer Monsoon rainfall (ISMR). All India annual and monsoon rainfall does not show significant long-term trends during the last century, although both decreasing and increasing trends are observed locally over different parts of India (Guhathakurta and Rajeevan 2008). However, a decreasing country-scale trend in rainfall was found for the last decades and additionally an increasing trend in extreme rainfall events and a decreasing trend in low intensity precipitation are reported (Kulkarni et al. 2012; Krishnaswamy et al. 2015; Roxy et al. 2015). Similarly, for neighbouring Bangladesh and Pakistan the frequency and intensity of extreme rainfall events have increased 
significantly in recent decades (Abbas et al. 2014; Dastagir 2015; Shahid et al. 2016; Amin et al. 2018).

Future climate projections over continental South Asia, based on the Coupled Model Intercomparison Project 5 (CMIP5) ensemble, show about $2{ }^{\circ} \mathrm{C}$ warmer conditions above the late 20th century period in the mid-21st century under the Representative Concentration Pathway (RCP) 8.5 forcing and more than $3{ }^{\circ} \mathrm{C}$ warming at the end of the century (Collins et al. 2013). The multi-model ensemble mean projects an $8-10 \%$ increase in the ISMR at the end of century, although the inter-model spread is large (Menon et al. 2013). At the same time almost all CMIP5 models that project an increase in the ISMR also project a contradicting weakening of the large-scale thermodynamic driver of the Indian summer monsoon, namely the upper tropospheric temperature gradient over the South Asia monsoon region (Sabeerali et al. 2015).

Increasing complexity and high computational costs limit generation of large high-resolution Global Climate Models (GCMs) ensembles for long multi-decadal time scales. Typical grid spacing in CMIP5 GCMs is about $100-250 \mathrm{~km}$ which is not sufficient to adequately represent all important processes relevant for regional and local scales. Therefore, the CMIP5 GCM projections have recently been complemented by dynamical and empirical-statistical downscaling within the Coordinated Regional climate Downscaling Experiment (Giorgi et al. 2009; Jones et al. 2011). The aim of CORDEX is to provide climate information on regional to local scales relevant for vulnerability, impact and adaptation studies, and the initial suggested grid spacing was $50 \mathrm{~km}$. However, a higher resolution grid spacing of $25 \mathrm{~km}$ is recently recommended. The number of CORDEX Regional Climate Model (RCM) simulations for South Asia is continuously growing with more simulations available (17 under RCP8.5 for $50 \mathrm{~km}$ and 6 for $25 \mathrm{~km}$, status of November 2019).

Over the South-Asian CORDEX domain, RCMs show varied skill in reproducing the climatology of the recent decades. A number of studies showed that RCMs in general can adequately capture temporal-spatial characteristics of precipitation relevant for the region and improve precipitation climatology of their driving GCMs (Dash et al. 2015; Hassan et al. 2015; Maharana and Dimri 2016; Karmacharya et al. 2017; Varikoden et al. 2018; Ghimire et al. 2018). However, other studies show more complex picture with RCMs not always improving, and sometimes even deteriorating precipitation climatology of their driving GCMs (Mishra et al. 2014; Mishra 2015; Singh et al. 2017). It is necessary to note here that proper evaluation of the ability of a RCM to simulate the present/recent climatology is impossible without a reanalysis (perfect boundary conditions) driven simulation. An ERA-Interim reanalysis driven simulation was used only in Maharana and Dimri (2016) and Karmacharya et al.
(2017) in the above studies while others used only GCMdriven simulations.

RCMs are developed to reproduce the large-scale climatology of the GCMs and to provide additional smaller-scale information often referred to as "added value" (Giorgi and Mearns 1991). There is no clear unique definition of the added value as it depends on many factors: regions, spatial and temporal scales, processes and variables (Di Luca et al. 2015; Rockel 2015; Rummukainen 2016). One can define added value of downscaling as reduction of large-scale GCM biases and indeed this may occur. However, not necessarily due to better description of regional process in RCMs but it could also be due to a simple cancelation of biases of opposite sign in GCMs and RCMs. In some cases RCMs may also amplify GCM biases or even change their sign. All the above factors can potentially contribute to differences in simulated past/recent climatology between GCMs and RCMs and can also lead to differences in future climate projections (Teichmann et al. 2013; Sørland et al. 2018).

In this study we introduce the SMHI-RCA4 ensemble for the CORDEX South Asia domain. We outline the main characteristics of the GCM and RCM ensembles focusing on differences and similarities in simulated seasonal mean temperature and precipitation between the RCA4 ensemble and the driving GCMs. We aim to show how one RCM can change GCMs biases in the simulated recent/present climate and modify the signal in climate change projections generated by GCMs. We limit the study to an overview and leave more in-depth detailed process analysis to forthcoming studies.

\section{Data and methods}

\subsection{Study area}

The study focuses on the central part of the South Asia CORDEX domain (Fig. 1) encompassing India, Pakistan, Nepal, Bangladesh, Bhutan and Myanmar. The region spans over a variety of different climatic zones, including arid deserts and dry lands, cold alpine mountains, and humid tropical islands, among others. The rainfall over the region is highly variable both on spatial and temporal scales with the Indian summer monsoon (June-July-August) contributing to about $75 \%$ precipitation of the annual amount. Spatially, the nature of monsoonal precipitation varies from region to region wherein the complex land-atmosphere interactions play a significant role. For spatial average analysis the study area is divided in nine subregions based on climatological features in the area (Fig. 1 and Table 2). A number of the subregions have been already used in different studies as CLI, SWI, SEI (Krishnamurti and Shukla 2000) and SPI and NPI (Sajjad et al. 2011), while configuration for other 


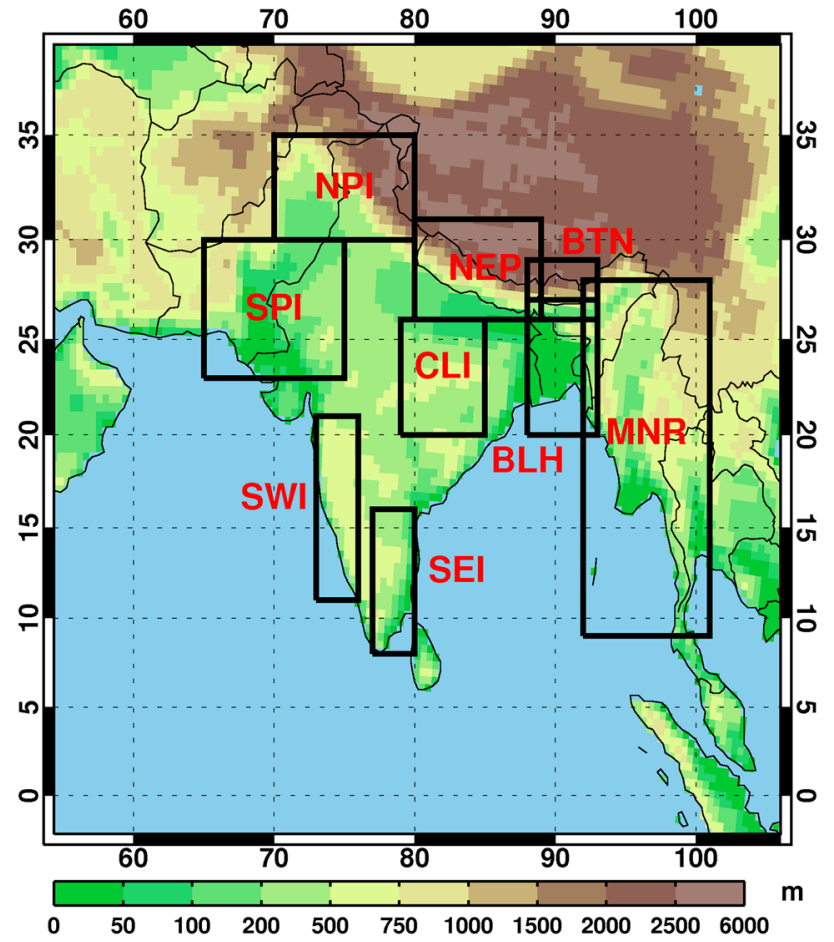

Fig. 1 The study area with RCA4 topography at 50-km resolution (colour) and nine subregions used for spatially averaged analysis. (CLI Central India, SWI South West India, SEI South East India, NPI North Pakistan and India, SPI South Pakistan and India, NEP Nepal, $B L H$ Bangladesh, BTN Bhutan, and MNR Myanmar)

Table 1 List of CMIP5 GCMs downscaled by RCA4 over the CORDEX South Asia domain

\begin{tabular}{lll}
\hline Model name & Acronym used & Resolution lon $\times$ lat \\
\hline CanESM2 & CanESM & $2.8^{\circ} \times 2.8^{\circ}$ \\
CNRM-CM5 & CNRM & $1.4^{\circ} \times 1.4^{\circ}$ \\
EC-EARTH & EC-EARTH & $1.1^{\circ} \times 1.1^{\circ}$ \\
MIROC5 & MIROC & $1.4^{\circ} \times 1.4^{\circ}$ \\
HadGEM2-ES & HadGEM & $1.875^{\circ} \times 1.25^{\circ}$ \\
MPI-ESM-LR & MPI-ESM & $1.875^{\circ} \times 1.875^{\circ}$ \\
NorESM1-M & NorESM & $2.50^{\circ} \times 1.895^{\circ}$ \\
GFDL-ESM2M & GFDL & $2.50^{\circ} \times 2.00^{\circ}$ \\
IPSL-CM5A-MR & IPSL & $2.50^{\circ} \times 1.25^{\circ}$ \\
CSIRO-Mk3-6-0 & CSIRO & $1.8^{\circ} \times 1.8^{\circ}$ \\
\hline
\end{tabular}

regions covering countries in the eastern part of the domain were received through personal communications.

\subsection{GCM and RCM simulations}

Two ensembles of climate simulations, one global and one regional, are utilized. The global ensemble includes ten GCMs from the CMIP5 project, listed in Table 1, with both a control period with prescribed forcing representative of conditions during 1951-2005 and the RCP8.5 scenarios for 2006-2100 (Moss et al. 2010). In the regional ensemble all ten GCMs are downscaled over the South Asia CORDEX domain by the Rossby Centre Regional Climate Model-RCA4 (Samuelsson et al. 2015; Strandberg et al. 2014; Kjellström et al. 2016), at about $50 \mathrm{~km}$ resolution. The first evaluation runs over the CORDEX South Asia domain showed that RCA4 has a strong cold bias over Tibet and a strong dry bias over the continent. The standard version of RCA4 (v1) used for most of the CORDEX domains has been slightly retuned for the CORDEX South Asia domain and named as "v2". The retuning includes changes in surface parameterization and in deep convection parameterization allowing deep convection to initiate more easily.

There was no skill-based selection of the CMIP5 GCMs for downscaling by RCA4 over the CORDEX South Asia domain. The 10 GCMs were simply downscaled in the order of their appearance (6-h model levels) on the Earth System Grid Federation (ESGF) or directly from the CMIP5 modelling groups. The same set of the $10 \mathrm{GCMs}$ has been downscaled by RCA4 at $50 \mathrm{~km}$ over other CORDEX domains e.g. Africa (e.g. Nikulin et al. 2019; Tamoffo et al. 2019), Europe (e.g. Kjellström et al. 2016; Sørland et al. 2018), South (e.g. Feron et al. 2019; Llopart et al. 2020) and Central (e.g. Corrales-Suastegui et al. 2019) America.

Daily mean sea surface temperature from the driving GCMs is used as lower boundary conditions. Downscaling of the ERA-Interim reanalysis (ERAINT, Dee et al. 2011) by RCA4 is also included to evaluate the ability of RCA4 to simulate the observed climate when driven by so called perfect boundary conditions. No nudging towards the GCMs or ERAINT was applied. The GCMs have varying horizontal resolution ranging from $1^{\circ}$ to $3^{\circ}$ (see Table 1 for details) and for spatial maps all GCMs are remapped from the native grids to a regular $2^{\circ}$ by $2^{\circ}$ grid by bicubic interpolation whereas the native grids were used for spatially averaged analysis over the nine specified subregions.

\subsection{Observations and reanalysis data}

Evaluation of RCM simulations over South Asia study region is a challenging task due to lack of high-quality long-term observational products with suitable temporal and spatial resolutions. In the present study, we use three common gridded observational datasets: the Global Precipitation Climatology Centre, GPCC, version 7 (Schneider et al. 2014), the Climate Research Unit Time-Series, CRU TS, version 3.23 (Harris et al. 2014), and University of Delaware, UDEL, version 4.01 (Legates and Willmott 1990). All these three datasets are at $0.5^{\circ}$ horizontal resolution. A reanalysis product from ECMWF, ERA-Interim (Dee et al. 2011) is also used. In contrast to climate models, ERAINT 


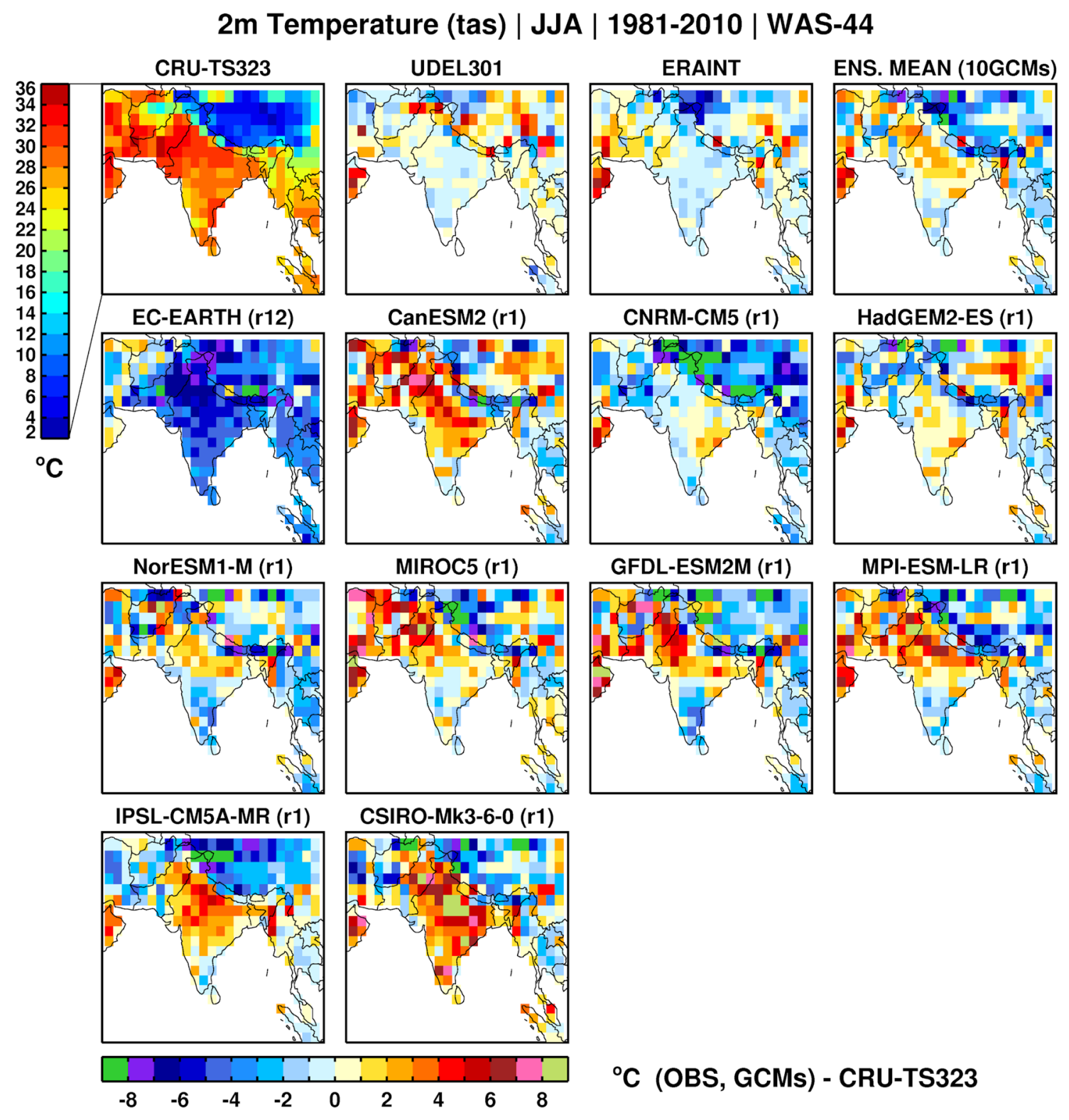

Fig. 2 CRU mean JJA temperature for 1981-2010 (top, left-hand panel), and differences compared to CRU in other observations/reanalysisUDEL/ERAINT (top, middle panels), ensemble mean of $10 \mathrm{GCMs}$ (top, right-hand panel) and 10 individual GCMs (middle and bottom rows)

precipitation is a short term forecast product and there are several ways to derive ERAINT precipitation (e.g. different spin-up, base time and forecast steps) that can lead to different precipitation estimates. ERAINT precipitation is derived by the simplest method, without spin up as in Nikulin et al. (2012). Multiple observation products, even if partly based on the same stations, allow us to get some rough estimation of observational uncertainties. All observation and reanalyse datasets were remapped from their native grids to the CORDEX $50 \mathrm{~km}$ grid by bicubic interpolations and aggregated to the common $2^{\circ} \mathrm{GCM}$ grid by conservative remapping. The native grids were employed for spatially averaged analysis over the nine specified sub-regions.

\subsection{Measure of robustness of climate change signal}

In this study we use an approach developed in Nikulin et al. (2019) and define the climate change signal as robust if the following two conditions are fulfilled: (1) more than $80 \%$ of model simulations agree on the sign of the change and (2) the signal to noise ratio (SNR), i.e., the ratio of the mean to the standard deviation of the ensemble of climate change signals, is equal to or larger than one. If only the first condition is met we use the term "consistent". 


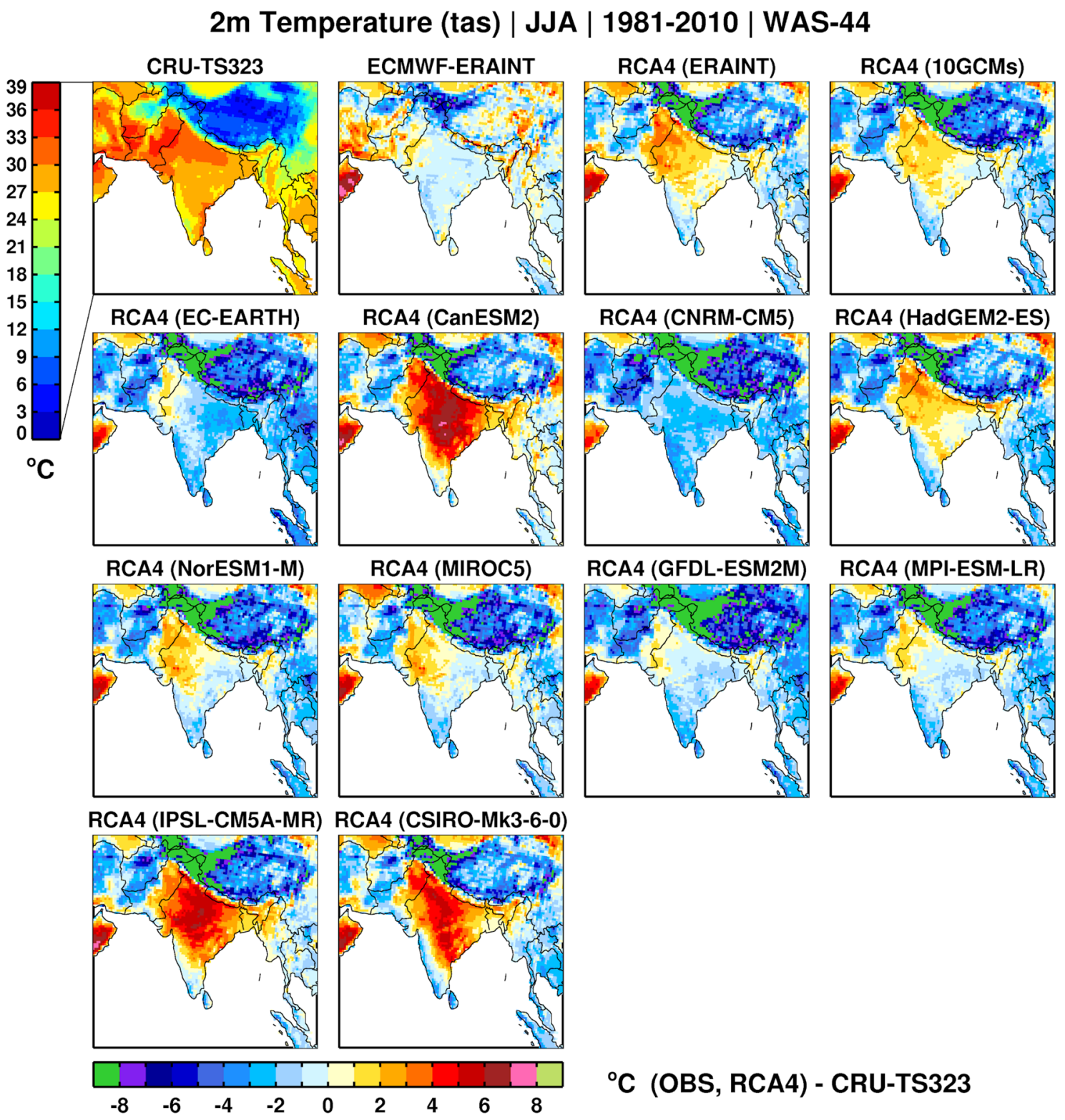

Fig. 3 CRU mean JJA temperature for 1981-2010 (top, left panel), and differences compared to CRU in ERAINT (top, left-middle panel), RCA4 driven by ERAINT (top, right-mid panel), ensemble

\section{Evaluation of the GCM and RCA4 ensembles}

\subsection{Temperature}

The main focus in our study is on the June-August (JJA) period with the largest contribution to the Indian summer monsoon rainfall over the sub-continent. Figure 2 shows CRU temperature for JJA and differences from CRU in the other datasets: the UDEL observation, the ERA-Interim reanalysis, the $10 \mathrm{GCM}$ simulations and the GCM multimodel ensemble. The seasonal mean temperature, according mean of RCA4 driven by 10 GCMs (top, right panel) and 10 individual RCA4 simulations (middle and bottom rows)

to CRU, varies strongly across the region with the coldest conditions in the high-altitude Himalayan region $\left(2-4{ }^{\circ} \mathrm{C}\right)$ and the hottest ones in northwest India and Pakistan (up to $36{ }^{\circ} \mathrm{C}$ ). Both UDEL and ERAINT are in good agreement with CRU over the mainland India (differences mostly within $1{ }^{\circ} \mathrm{C}$ ) while large discrepancies across the three datasets (up to $5-6{ }^{\circ} \mathrm{C}$ ) are found locally in the Himalayan region. Such large differences in the region with complex topography represent a simple measure of observational uncertainties and compromises accurate evaluation of the simulated temperature in the northern part of the domain. 


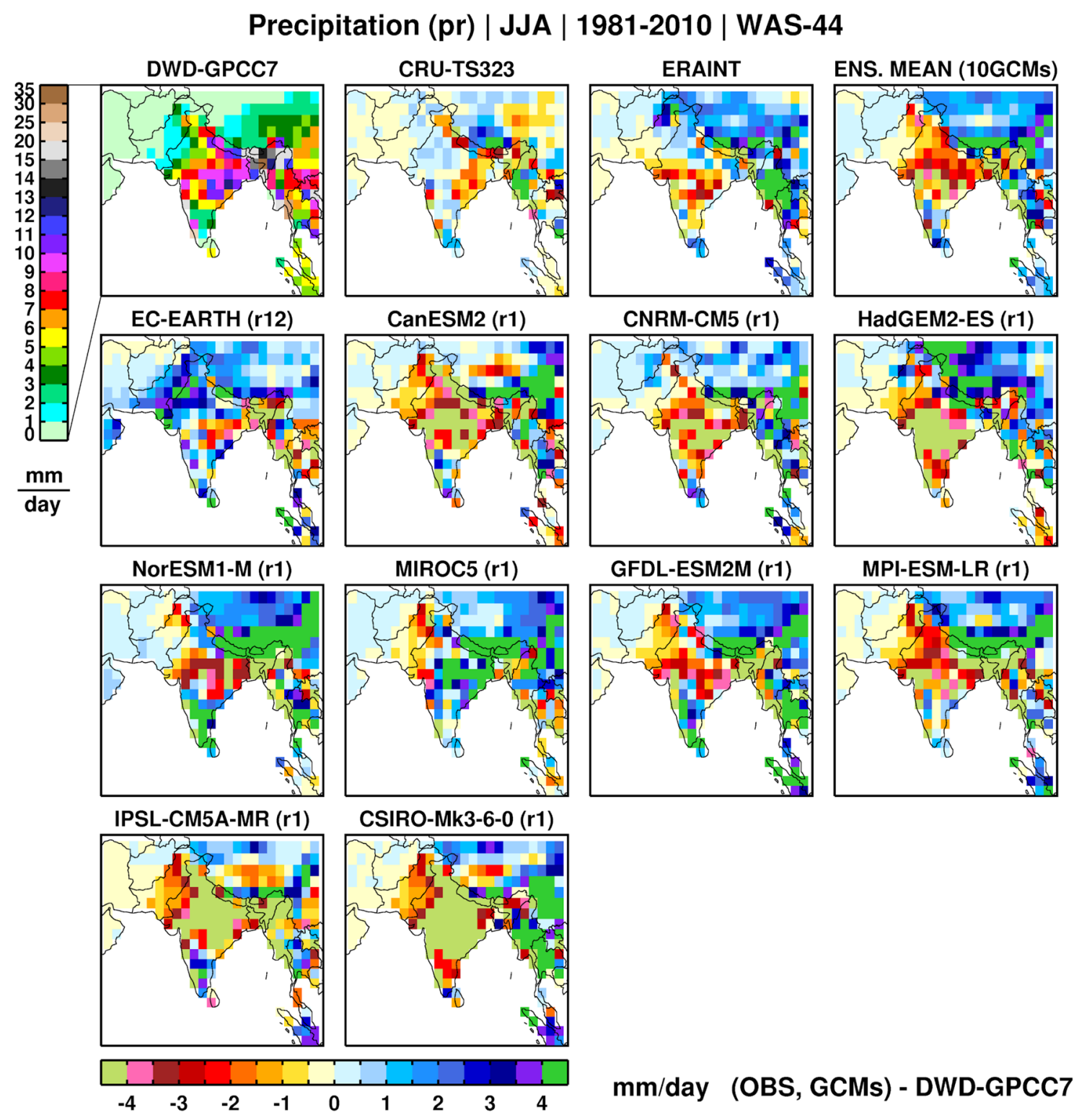

Fig. 4 GPCC mean JJA precipitation for 1981-2010 (top, left panel), and differences compared to GPCC in other observations/reanalysisCRU/ERAINT (top, middle panels), ensemble mean of 10 GCMs (top, right panel) and 10 individual GCMs (middle and bottom rows)

The EC-EARTH is the coldest model in the ensemble with a strong cold bias (up to $8^{\circ} \mathrm{C}$ ) in the entire region. This feature is part of large-scale cold bias in EC-EARTH covering the tropics (Hazeleger et al. 2012). Contrasting to EC-EARTH, CSIRO has the strongest large-scale warm bias in the ensemble reaching more than $8{ }^{\circ} \mathrm{C}$ in northern India. Other models show mixed biases across the region with some tendency to overestimate temperature in northwest India and Pakistan and underestimate it in the Himalayas. The GCM ensemble shows a moderate warm bias $\left(2-3{ }^{\circ} \mathrm{C}\right)$ in northern parts of India and a stronger cold bias in the Himalayas (up to $5-6{ }^{\circ} \mathrm{C}$ ), although at some grid boxes the GCM cold bias is comparable with the difference between
CRU and UDEL. We note that the moderate warm bias in the ensemble mean over northern India results from combining a large cold bias in EC-EARTH with warm biases in other GCMs. Only three models of ten-HadGEM, CNRM and MIROC are able to simulate the observed temperature to within $\pm 2{ }^{\circ} \mathrm{C}$ over most of India.

Compared to CRU, RCA4 driven by ERAINT overestimates temperature in northwest India and Pakistan and strongly underestimates it in the Himalayan region while biases are mostly within $1{ }^{\circ} \mathrm{C}$ over mainland India (Fig. 3). The RCA4 ensemble mean temperature is almost identical to the ERAINT-driven simulation. However, again similar to the GCM ensemble, the small RCA4 ensemble mean bias 


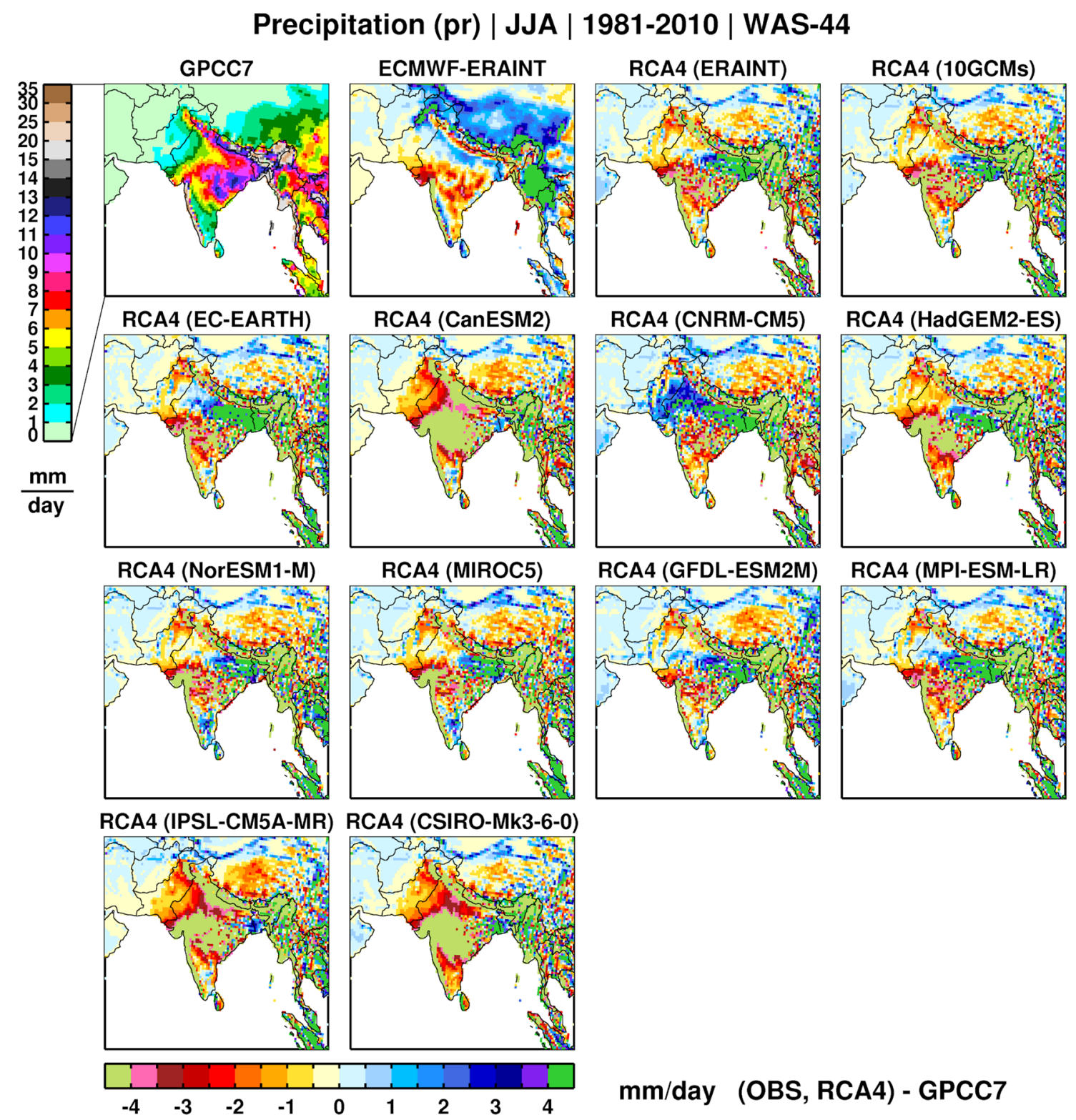

Fig. 5 GPCC mean JJA precipitation for 1981-2010 (top, left panel), and differences compared to GPCC in ERAINT (top, left-middle panel), RCA4 driven by ERAINT (top, right-mid panel), ensemble

originates from cancelation of biases with different sign in the individual simulations. Three RCA4 simulations (driven by CanESM, IPSL and CSIRO) are strongly overestimating temperature thus reproducing similar biases as in the driving GCMs. In contrast, downscaling by RCA4 considerably reduces the strong cold bias in EC-EARTH and the warm biases over northwest India and Pakistan in MIROC, GFDL and MPI-ESM. There are also RCA4 simulations where biases become larger than in the driving GCMs (CNRM and HadGEM). A common feature across all RCA4 simulations is the Himalayan region where cold GCM biases are amplified. Clearly, the impact of downscaling by RCA4 is mean of RCA4 driven by 10 GCMs (top, right panel) and 10 individual RCA4 simulations (middle and bottom rows)

mixed: with either reduced, similar or amplified temperature biases compared to the underlying GCMs.

\subsection{Precipitation}

Figure 4 represents the JJA precipitation as estimated by the GPCC observational dataset and the difference from GPCC between the other datasets (CRU and ERAINT) and the 10 GCM simulations. GPCC shows large spatial variability in precipitation with the largest amounts in the eastern part of the domain reaching up to $25 \mathrm{~mm} /$ day. CRU and ERAINT shows mixed patterns with either more or 


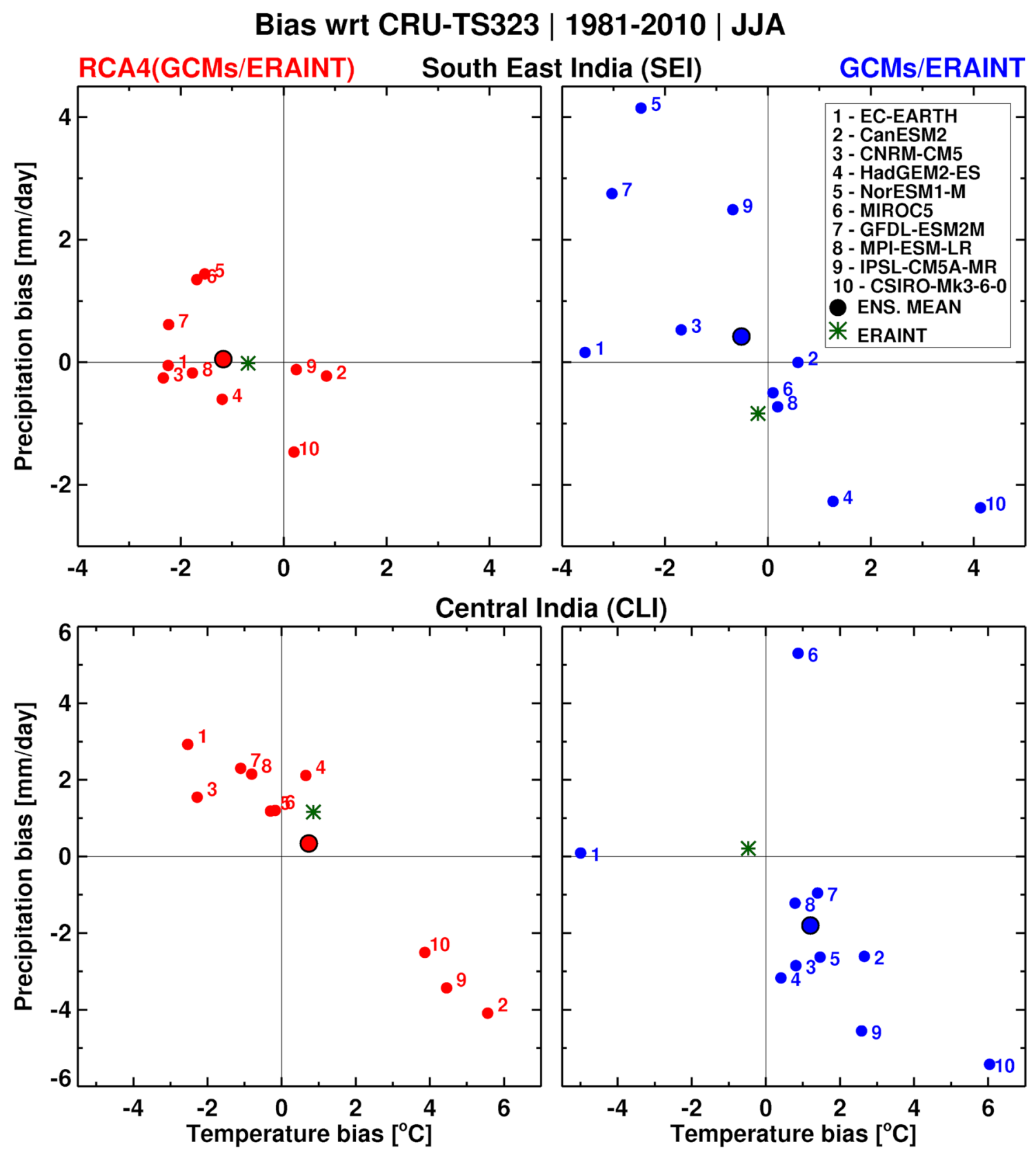

Fig. 6 Covariation of temperature and precipitation biases in the RCA4 (left) and GCM (right) ensembles relative to CRU over the SEI (top) and CLI (bottom) regions for 1981-2010

less precipitation than GPCC. For individual grid boxes differences across the datasets can reach up to $4 \mathrm{~mm}$ /day and even more and this may limits an accurate evaluation. Compared to GPCC the GCM ensemble mean has a large-scale dry bias (up to $4 \mathrm{~mm} /$ day and more) over most of India whereas there are equally wet biases in the Himalayas and in the eastern part of the domain. EC-EARTH and MIROC show mostly wet biases over India while in contrast the rest of the GCMs show predominantly dry biases. Dry (wet) biases in precipitation often resembles warm (cold) biases in temperature (Fig. 2), although CNRM and HadGEM showing a strong dry bias despite relatively small biases in temperature, mostly within $1{ }^{\circ} \mathrm{C}$. GPCC at its native $0.5^{\circ}$ resolution resolves small-scale features in precipitation, for example a rain belt in SouthWest India and a sharp contrast in precipitation on and near the slopes of the Himalayas (Fig. 5). Downscaling of ERAINT by RCA4 almost completely removes the ERAINT wet bias in the Himalayas while the dry bias in central India is amplified. Additionally, RCA4 (ERAINT) 


\section{Temperature (tas) | WAS-44}

\section{JJA | CTL: 1981-2010 | SCN: 2071-2100 | rcp85}
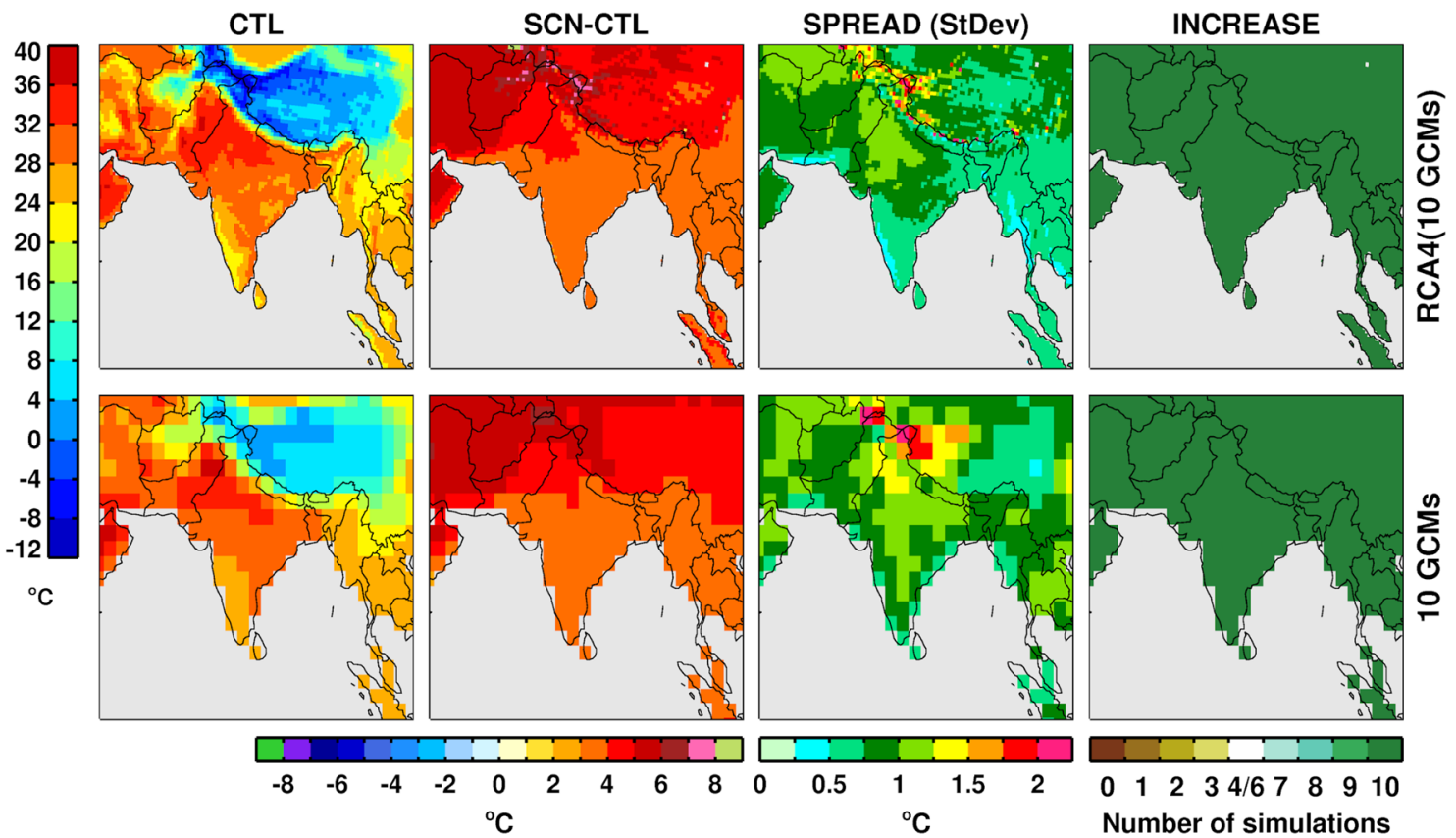

Fig. 7 Ensemble mean JJA temperature in 1981-2010 (left), its change in 2071-2100 (second column), the spread (in terms of standard deviation) across the ensemble members (third column) and number of simulations agree on an increase (rightmost column). The

generates a wet bias in north-eastern India, a feature not present in ERAINT. Instead of replicating the GCM bias patterns, the RCA4 bias pattern in precipitation is close to that seen in the ERAINT downscaling, regardless of forcing GCM. However, the strongest dry bias in central India is found in the RCA4 simulations driven by the driest GCMs (CanESM, HadGEM, IPSL and CSIRO). Despite some coherence with the GCMs, the RCA4 bias pattern is still very similar to that in the ERAINT-driven simulation. This indicates that the RCA4 physics puts its strong imprint on the simulated precipitation.

\subsection{Covariation of temperature and precipitation biases}

The impact of the RCA4 downscaling on the GCM biases over two subregions is illustrated in Fig. 6 showing scatter plots for temperature and precipitation biases in the global and regional ensembles averaged over South-East India (SEI) and over Central India (CLI). CRU is taken as reference here since both temperature and precipitation are available for this dataset. In general for both subregions and for both ensembles dry (wet) biases in precipitation correspond to warm (cold) biases in temperature. However, impact of
RCA4 ensemble is presented in top row and the GCM ensemble in bottom one. All grid boxes show robust temperature change (SCNCTL) satisfying the two criteria (the agreement and signal to noise ratio)

downscaling on the GCM biases is different in the two regions. In the SEI region RCA4 tends to strongly reduce the negative and positive GCM biases in both precipitation and temperature simulating the observed climatology more accurately in comparison to the individual GCMs. Over the CLI region most of the GCMs cluster around warm and dry biases. Contrastingly, RCA4 changes biases towards wetter and colder conditions, showing a strong negative correlation between temperature and precipitation biases. Nevertheless, for both regions, RCA4 almost always substantially reduces the largest GCM biases as for NorESM and CSIRO in SEI and MIROC and CSIRO in CLI. Contrasting the GCM biases versus RCA4 ones (not shown) does not show a consistent dependency of the RCA4 temperature biases on the respective driving GCM biases. The coldest/warmest RCA4 simulations partly correspond to the coldest/warmest GCM simulations in six regions of the nine but not in NPI, SPS and BLH. For precipitation biases, a similar moderate dependence (the wettest/driest RCA4 simulations correspond to the wettest/driest GCM simulations) is found only in SEI and NPI. These examples show that there is no systematic general reduction or amplification of the GCM biases by the RCA4 downscaling. Instead one can find either reduction or amplification of the GCM biases depending on region and/or on driving GCM. 
2m Temperature (tas) anomalies wrt 1981-2010 | 31-yr. mov. mean | JJA | 80\% | SNR>1
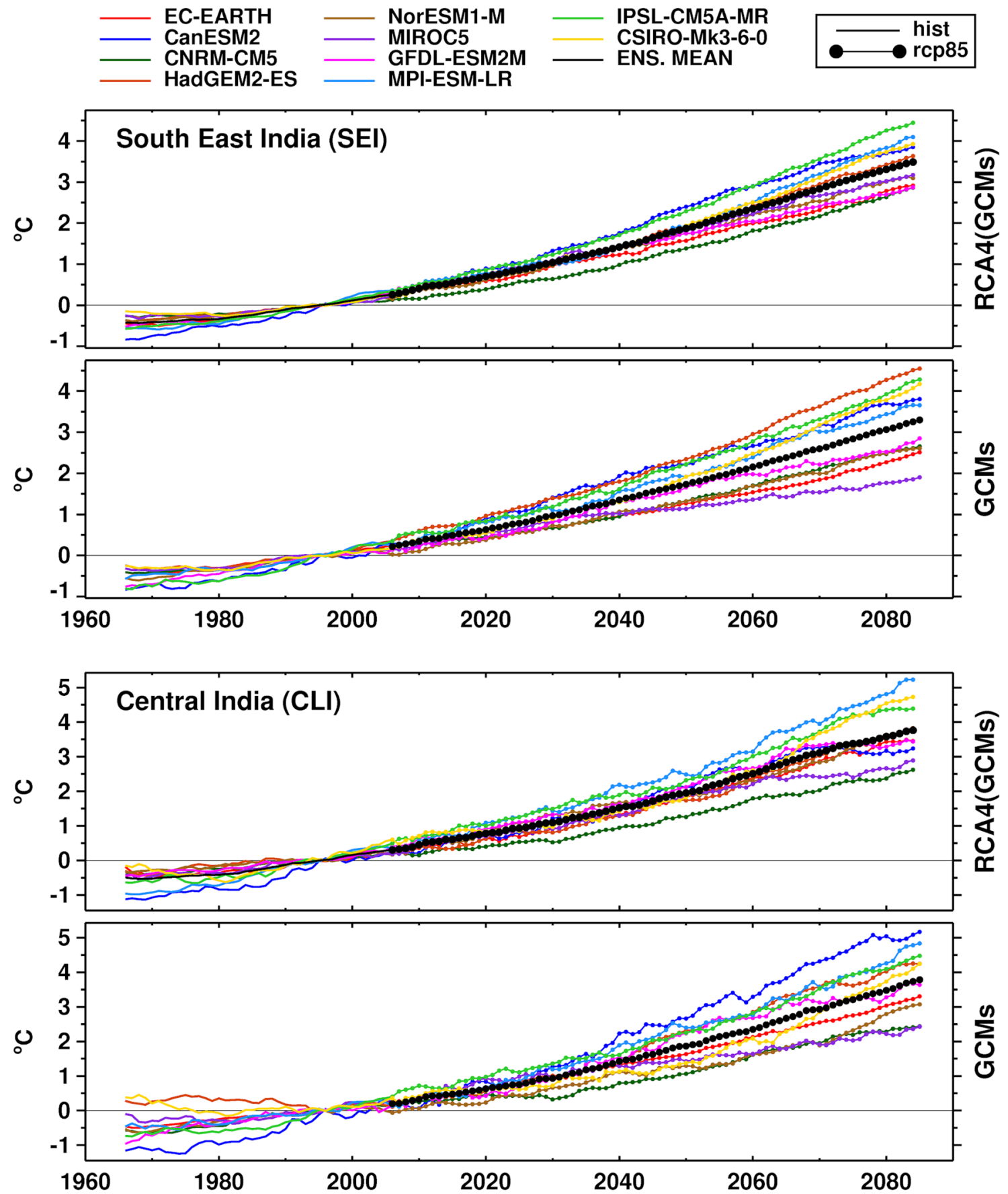

Fig. 8 Time series of projected JJA mean temperature anomalies relative to 1981-2010 for the RCA4 (first and third rows) and GCM ensemble (second and forth row) over the SEI (two top panels) and

\section{Future climate projections in the GCM and RCA4 ensembles}

\subsection{Temperature projections}

Figure 7 represents projected climate changes in
CLI (two bottom panels) regions. Time-series are smoothed by a 31-year moving average. For the ensemble mean, robust climate change signal (the two criteria are met) is shown by larger circles

temperatures for the RCA4 and GCM ensembles under the RCP8.5 scenario in 2071-2100 with respect to 1981-2010. The spread in the projected changes across the individual members of the ensembles is expressed as the standard deviation and a simple estimate of uncertainties is presented as the number of simulations that agree on an increase. Both 
Table 2 Projected climate change and spread (in terms of standard deviations) in JJA mean temperature $\left({ }^{\circ} \mathrm{C}\right)$ and precipitation ( $\mathrm{mm} /$ day) in 2071 2100 relative to $1981-2010$ for the RCA4 and GCM ensembles

\begin{tabular}{|c|c|c|c|c|c|c|c|c|}
\hline \multirow[t]{3}{*}{ Region (acronym) coordinates } & \multicolumn{4}{|c|}{ Temperature, $\left({ }^{\circ} \mathrm{C}\right)$} & \multicolumn{4}{|c|}{ Precipitation, $\mathrm{mm} /$ day } \\
\hline & \multicolumn{2}{|l|}{ RCA4 } & \multicolumn{2}{|c|}{ GCMs } & \multicolumn{2}{|l|}{ RCA4 } & \multicolumn{2}{|l|}{ GCMs } \\
\hline & Mean & Spread & Mean & Spread & Mean & Spread & Mean & Spread \\
\hline $\begin{array}{l}\text { Central India (CLI) } \\
79-85^{\circ} \text { E, } 20-26^{\circ} \mathrm{N}\end{array}$ & 3.8 & 0.83 & 3.81 & 0.98 & $3.4(9)$ & 3.2 & $1.4(6)$ & 2.3 \\
\hline $\begin{array}{l}\text { South West India (SWI) } \\
73-76^{\circ} \mathrm{E}, 11-21^{\circ} \mathrm{N}\end{array}$ & 3.27 & 0.53 & 3.3 & 0.82 & $5.2(10)$ & 3.0 & $3.8(8)$ & 4.7 \\
\hline $\begin{array}{l}\text { South East India (SEI) } \\
77-80^{\circ} \mathrm{E}, 8-16^{\circ} \mathrm{N}\end{array}$ & 3.54 & 0.58 & 3.31 & 0.9 & $1.4(10)$ & 0.6 & $2.2(10)$ & 1.6 \\
\hline $\begin{array}{l}\text { North Pakistan and India (NPI) } \\
70-80^{\circ} \mathrm{E}, 30-35^{\circ} \mathrm{N}\end{array}$ & 4.84 & 0.93 & 4.67 & 0.99 & $1.9(8)$ & 1.9 & $1.5(9)$ & 2.0 \\
\hline $\begin{array}{l}\text { South Pakistan and India (SPI) } \\
65-75^{\circ} \mathrm{E}, 23-30^{\circ} \mathrm{N}\end{array}$ & 3.95 & 0.84 & 3.83 & 0.91 & $1.2(8)$ & 2.1 & $0.3(6)$ & 1.3 \\
\hline $\begin{array}{l}\text { Nepal (NEP) } \\
80-89^{\circ} \text { E, } 26-31^{\circ} \mathrm{N}\end{array}$ & 4.37 & 0.69 & 4.25 & 0.68 & $3.5(9)$ & 2.2 & $5.1(9)$ & 3.8 \\
\hline $\begin{array}{l}\text { Bangladesh (BLH) } \\
88-93^{\circ} \text { E, } 20-27^{\circ} \mathrm{N}\end{array}$ & 3.3 & 0.54 & 3.49 & 0.91 & $6.0(10)$ & 3.8 & $2.6(6)$ & 5.7 \\
\hline $\begin{array}{l}\text { Bhutan (BTN) } \\
88_{-93^{\circ} \text { E, } 26-29^{\circ} \mathrm{N}}\end{array}$ & 4.06 & 0.67 & 3.95 & 0.7 & $5.1(10)$ & 2.2 & $7.8(9)$ & 8.4 \\
\hline $\begin{array}{l}\text { Myanmar (MNR) } \\
92-101^{\circ} \mathrm{E}, 9-28^{\circ} \mathrm{N}\end{array}$ & 3.44 & 0.54 & 3.55 & 0.86 & $8.0(10)$ & 2.6 & $3.6(8)$ & 2.7 \\
\hline
\end{tabular}

Values in bracket for precipitation are number of simulations projecting an increase (for temperature all 10 simulations agree on an increase)

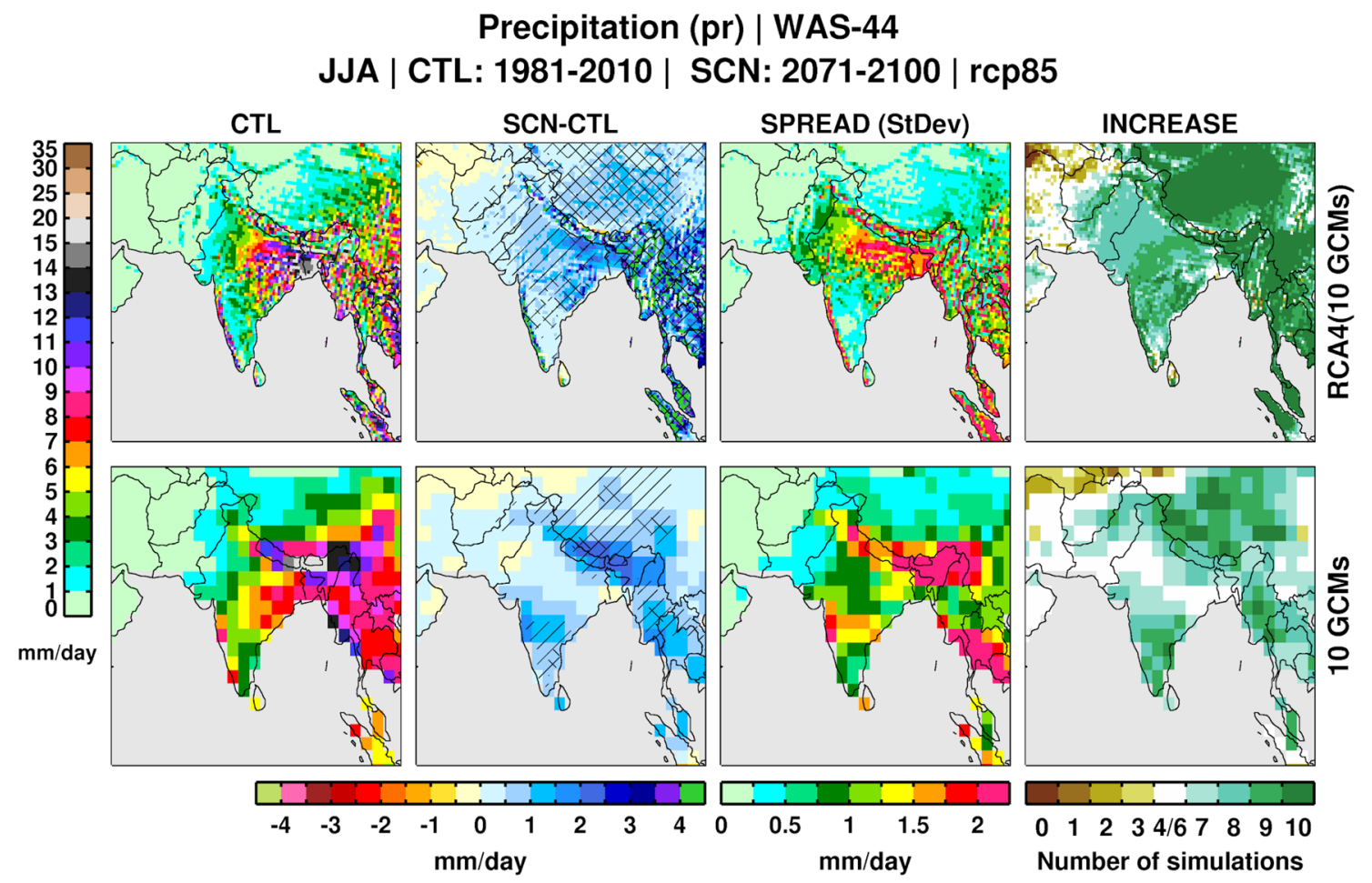

Fig. 9 Same as Fig. 7 but for precipitation. Areas where at least $80 \%$ of the simulations ( 8 of 10) agree on the sign of the change are marked by positively sloped hatching. Areas where the signal to noise ratio is equal or more than 1 are marked by negatively sloped hatching 
Precipitation (pr) anomalies wrt 1981-2010 | 31-yr. mov. mean | JJA | 80\% | SNR>1
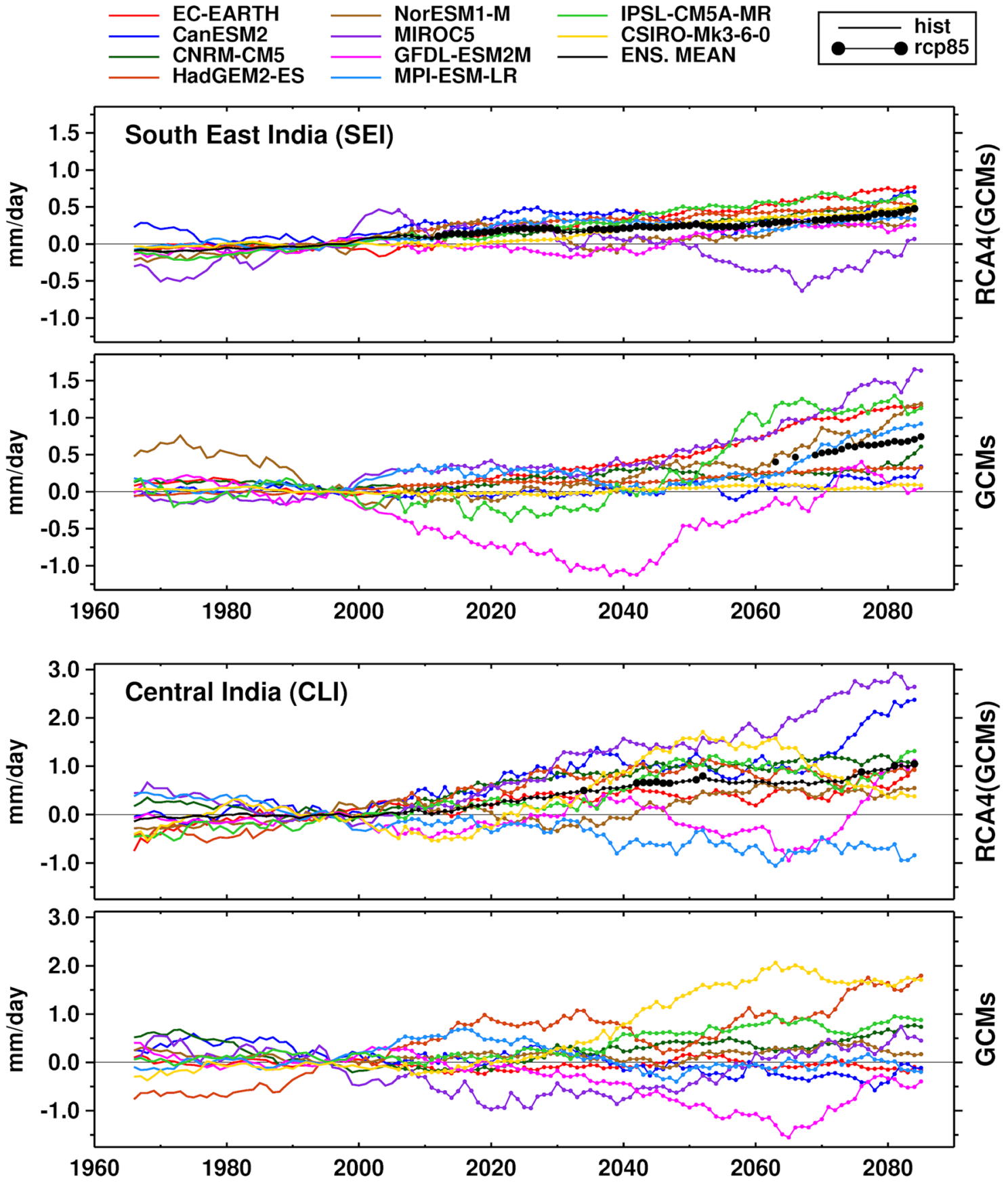

Fig. 10 Same as Fig. 8 but for precipitation

the global and the regional ensembles depict an increase in summer temperature across the region with a similar north-south gradient. Temperature increases by up to $4{ }^{\circ} \mathrm{C}$ in the southern part of the domain and up to $5-6^{\circ} \mathrm{C}$ in the northern part, although in the mountain region warming reaches up to $7-8{ }^{\circ} \mathrm{C}$ in the RCA4 ensemble. All individual simulations show increasing temperatures in all areas. However, there is some spread across the ensemble members.
The largest spread is confined to high-altitude areas in parts of the Himalayas in both ensembles. A difference between the ensembles is that RCA4 in general reduces the spread over India and the south-eastern part of the domain. Such a reduction is most likely related to the fact that the $10 \mathrm{GCMs}$ have different resolution and formulation while all RCA4 simulations have the same resolution and formulation. 


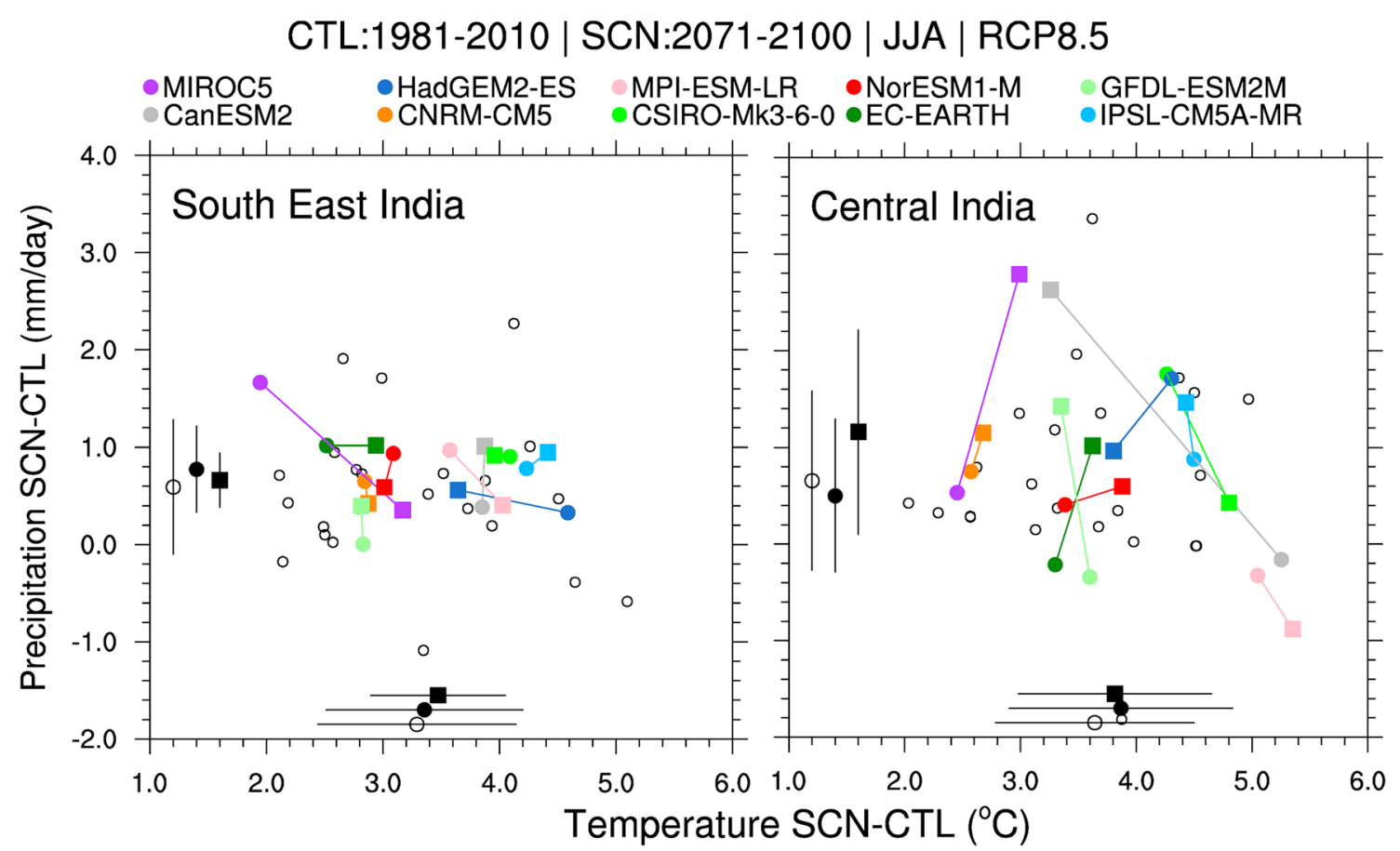

Fig. 11 Temperature and precipitation changes over South East India (SEI) and Central India (CLI) for summer (JJA) mean conditions in 2071-2100 relative to the control period (1981-2010). The error bars plotted inside the axis in the diagram illustrate the average and plus or minus 1 standard deviation for (1) the CMIP5 ensemble (2)

To investigate temporal evolution of projected temperature changes in both ensembles Fig. 8 shows time series of regional averages for South East and Central India smoothed by a 30 -year moving average. For both regions both ensembles show similar transient temperature increase with a difference between the two RCPs emerging around 2030. The ensemble mean warming is almost the same in the two ensembles (difference within $0.2{ }^{\circ} \mathrm{C}$ ) in these two regions and all others (see Table 2). The downscaling reduces the spread in all low-lying regions (CLI, SWI, SEI, BLH and MNR) while only minor changes are seen in high altitude regions (NPI, SPI, NED and BTN). A remarkable difference can be found for individual simulations. For example, HadGEM shows the strongest warming over the SEI region in the GCM ensemble $\left(4.5^{\circ} \mathrm{C}\right)$ while RCA4(HadGEM) shows more moderate warming $\left(3.6^{\circ} \mathrm{C}\right)$ close to the RCA4 ensemble mean $\left(3.5^{\circ} \mathrm{C}\right)$. Similarly, RCA4 reduces the strongest warming over CLI compared to the GCM ensemble (CanESM, $\left.5.1^{\circ} \mathrm{C}\right)$, to a more moderate warming $\left(3.2{ }^{\circ} \mathrm{C}\right)$, even below the RCA4 ensemble mean $\left(3.8^{\circ} \mathrm{C}\right)$. Such large differences may potentially have a strong impact on assessment of regional climate change if a single GCM is used the ten-member GCM ensemble that has been downscaled and (3) the 10-member RCA4 ensemble. Open circles are CMIP5 GCMs that have not been downscaled by RCA4. Filled circles represent GCMs that have been downscaled by RCA4 and these are connected by a line to RCA4 (filled squares)

for downscaling, and shows the importance of using large ensembles.

\subsection{Precipitation projections}

Figure 9 represents projected climate changes in precipitation for the RCA4 and GCM ensembles. For the control period both ensembles show a similar large-scale precipitation pattern with a maximum in northeast India and the eastern part of the domain. RCA4 provides more regional details like a more confined maximum along the Western Ghats in better agreement with GPCC7 (see Fig. 5) compared to the GCM ensemble. Similarly, the sharp gradient in precipitation is more realistic along the Himalayan slopes in the RCA4 ensemble.

Both ensembles project increasing precipitation over most of the domain, although with differing spatial patterns. The RCA4 ensemble shows robust increase over larger parts of the domain, especially in the north-eastern part. In contrast, the GCM ensemble, shows smaller patches with a robust signal. In the RCA4 ensemble a regional maximum is seen in the Ganges plains that is not coinciding with that in the GCM ensemble located more northwards into the mountains. Another difference 


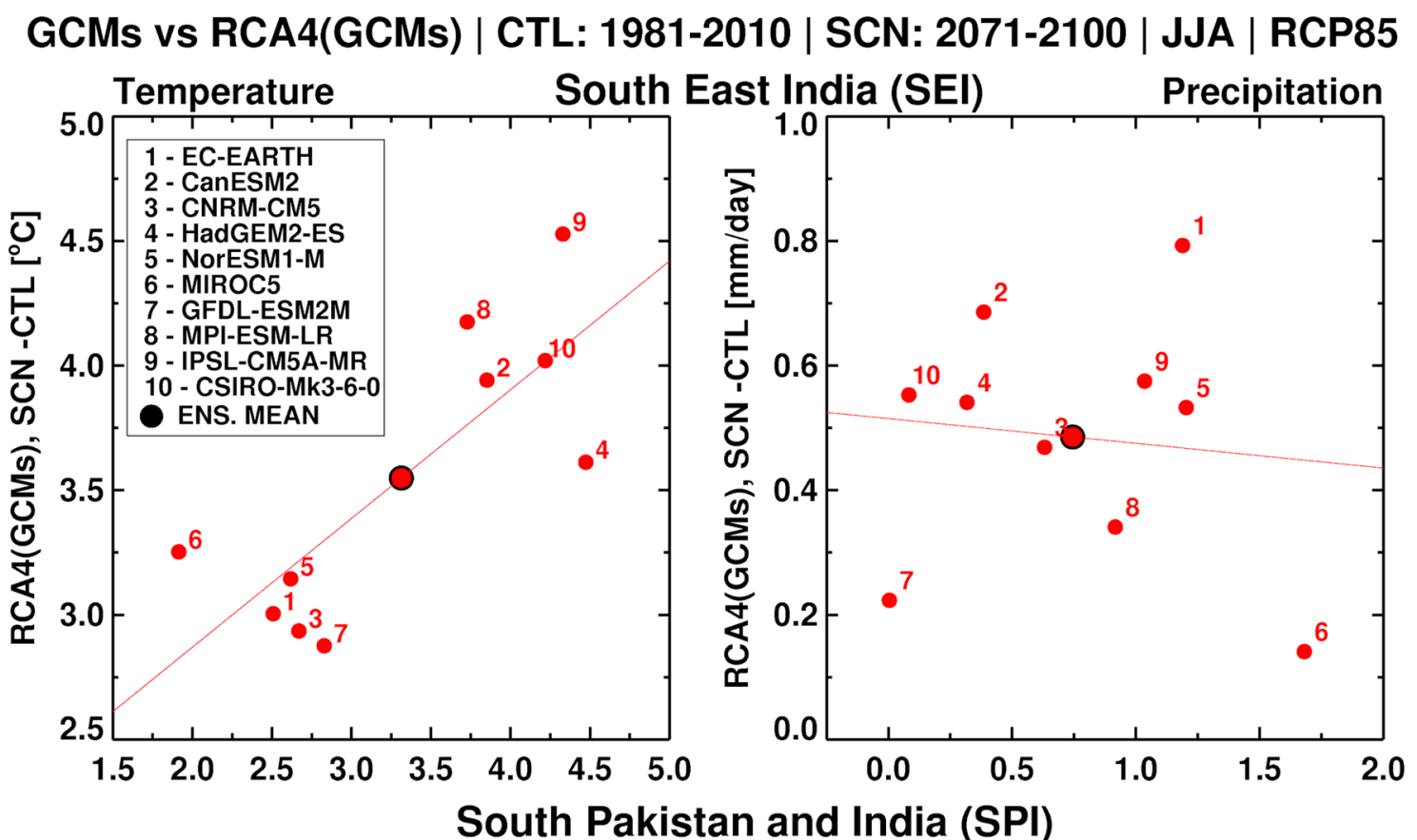

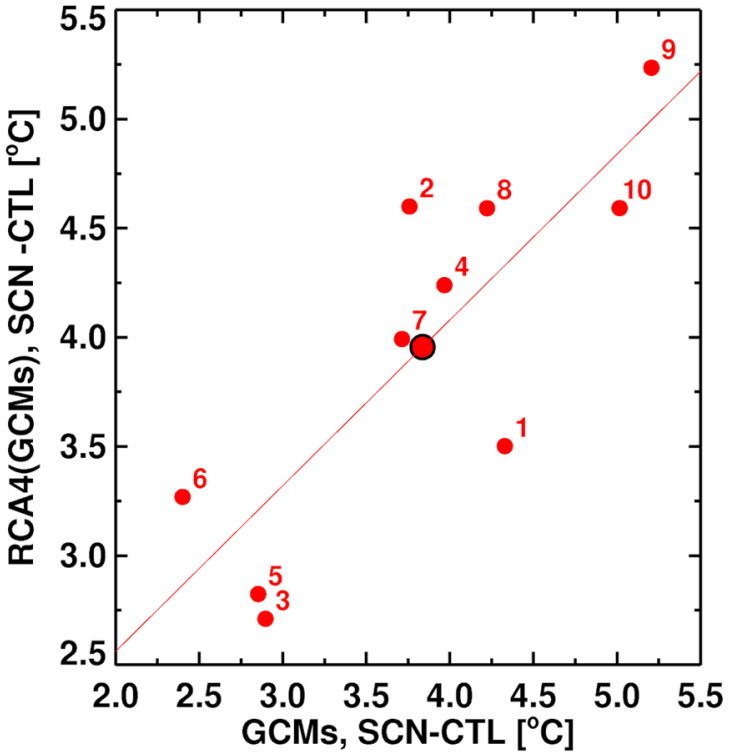

Fig. 12 Projected changes in temperature and precipitation generated by RCA4(GCMs) as a function of projected changes generated by the driving GCMs. Temperature and precipitation are averaged over

between the two ensembles is the absence of a regional maximum over central-southern India in the RCA4 ensemble. In general, the largest changes in precipitation coincide with the largest spread across the ensemble members. A pronounced difference between the two ensembles is the fact that more members agree on an increase in precipitation in the RCA4 ensemble. In the GCM ensemble there is a region in central-northern India where it is uncertain whether precipitation will increase or decrease. Contrastingly, most of the RCA4 simulations indicate an increase.

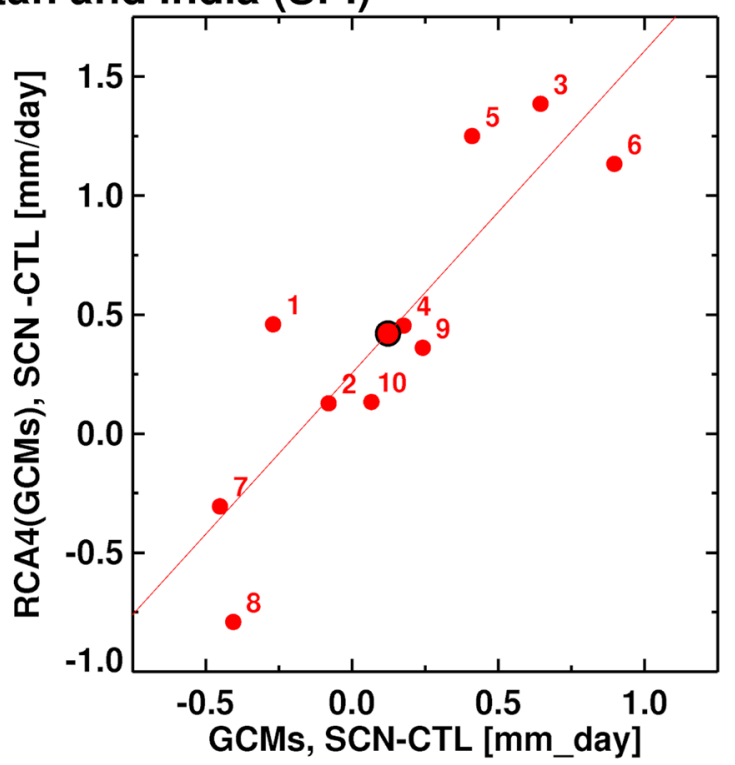

South East India (SEI, top) and Central India (CLI, bottom) for summer (JJA). Thin lines present a linear fit

Figure 10 shows time series of precipitation changes averaged for South East (SEI) and Central India (CLI). In both regions the ensemble means indicate increasing precipitation. In the SEI region RCA4 shows reduced spread compared to the GCM and a robust signal not seen in the GCM ensemble. In the CLI region, the spread in the RCA4 ensemble is increased and none of the ensembles show a robust signal. Table 2 further illustrates differences across the sub-regions. There is no systematic reduction or amplification of neither the ensemble mean change nor the 
Table 3 The slope and one-sigma uncertainty estimates for a linear fit to projected changes in temperature and precipitation generated by RCA 4 as a function of projected changes generated by the driving GCMs

\begin{tabular}{llllll}
\hline Region & \multicolumn{2}{l}{ Temperature } & & \multicolumn{2}{l}{ Precipitation } \\
\cline { 2 - 3 } \cline { 6 - 7 } \cline { 5 - 6 } & Slope & Sigma & & Slope & Sigma \\
\hline Central India & $\mathbf{0 . 5 3}$ & 0.23 & & -0.13 & 0.48 \\
South West India & $\mathbf{0 . 5 6}$ & 0.11 & & 0.02 & 0.22 \\
South East India & $\mathbf{0 . 5 1}$ & 0.14 & & -0.03 & 0.13 \\
North Pakistan and India & $\mathbf{0 . 8 8}$ & 0.13 & & $\mathbf{0 . 8 6}$ & 0.13 \\
South Pakistan and India & $\mathbf{0 . 7 6}$ & 0.18 & & $\mathbf{1 . 3 5}$ & 0.27 \\
Nepal & $\mathbf{0 . 8 7}$ & 0.19 & & $\mathbf{0 . 4 2}$ & 0.16 \\
Bangladesh & $\mathbf{0 . 5 1}$ & 0.11 & & 0.10 & 0.23 \\
Bhutan & $\mathbf{0 . 7 7}$ & 0.19 & & -0.03 & 0.09 \\
Myanmar & $\mathbf{0 . 5 6}$ & 0.1 & & -032 & 0.33 \\
\hline
\end{tabular}

The slope statistically significant at the 0.05 significance level is in bold

spread by downscaling. We note that for some individual simulations the response is very different in RCA4 compared to the driving GCMs. For example in Central India RCA4 downscaling MIROC and CanESM projects large increases in precipitation more or less absent in these two GCMs. Contrasting to temperature (Fig. 8), in some GCM simulations, precipitation undergoes strong multi-decadal variability as expressed by the striking anomalies in GFDL and IPSL lasting for decades over SEI. For this particular region and the GCMs downscaling by RCA4 almost completely suppresses these multi-decadal anomalies.

\section{Discussion}

The presented results are based on one single RCM driven by the 10 CMIP5 GCMs. Even if this is a relatively large set of driving GCMs it still only represents about a third of the GCMs in the full CMIP5 ensemble. Potentially, this can lead to underestimation of the spread in the climate change signal compared to the full ensemble. To illustrate this Fig. 11 shows projected changes in precipitation and temperature over SEI and CLI at the end of the century as simulated by RCA4, its 10 driving GCMs and the full CMIP5 ensemble. For temperature in the SEI region the 10-member GCM ensemble has almost identical mean and spread as the full CMIP5 ensemble. For the CLI region the spread is also almost the same but the mean is slightly higher. For both regions, the RCA4 ensemble has a tendency to reduce the spread relative to that in the driving GCMs, mostly pronounced in SEI.

For this SEI region the spread in precipitation changes is smaller in the 10-member GCM ensemble than in the full one. This is related to the fact that the driving GCM ensemble only includes models with moderate changes (0-1 $\mathrm{mm} /$ day) with the exception of MIROC. Furthermore, after downscaling, the spread is even more reduced. RCA4 strongly reduces the wet signal in MIROC while for other ensemble members differences between RCA4 and the underlying GCMs are relatively small. For CLI both GCM ensembles show a similar mean change and spread. In contrast to SEI, downscaling increases the spread and projects stronger increase in precipitation. Clearly, RCA4 has a pronounced imprint on the results with both moderate decreases (HadGEM, CSIRO and MPI) and strong increases (MIROC, CanESM and GFDL).

Another aspect (dimension) of downscaling is to what degree RCMs reproduce the climate change signal of their driving GCMs. To elucidate this, Fig. 12 shows temperature and precipitation changes projected by RCA4 as a function of the changes in the driving GCMs for SEI and SPI. There is a strong relationship between the changes in temperature for both regions, even if RCA4 sometimes alters the climate change signal by about $1^{\circ}$. For SPI, there is a strong relationship for the changes in precipitation, similar to temperature. In contrast, for SEI, there is no relationship between the changes in RCA4 and the driving GCMs. In general all nine subregions clearly show a strong positive relationship for temperature (see Table 3): RCA4 driven by GCMs with stronger warming shows stronger warming as well. Table 3 also shows that the slope for temperature is less than one for all nine regions, implying that in general RCA4 has a tendency to reduce the warming as projected by the GCMs. However, for changes in precipitation a statistically significant relationship between RCA4 and GCMs is confined only to the three northwesterly regions-SPI, NPI and NEP (Table 3).

Next, in Fig. 13, we investigate to what extent the climate change signal is related to biases in the control period. In the SEI region for both the GCM and RCA4 ensembles there is a statistically significant dependence of the projected temperature changes on biases. Colder biases are connected to weaker warming while warm biases are connected to stronger warming, similar to what has previously been found for southern Europe (Boberg and Christensen 2012). In contrast, no dependence is present in CLI, neither in the RCA4 nor in the GCM ensembles. A more comprehensive analysis, including all regions, shows that RCA4 has a similar significant dependence in six of the nine regions (Table 4) while the GCM ensemble shows no such dependency outside of the SEI region. For precipitation there is no significant dependency between projected changes and biases with the exception of the SWI for the GCM ensemble. We also note that all cases with significant dependencies in Table 4 do have a positive 

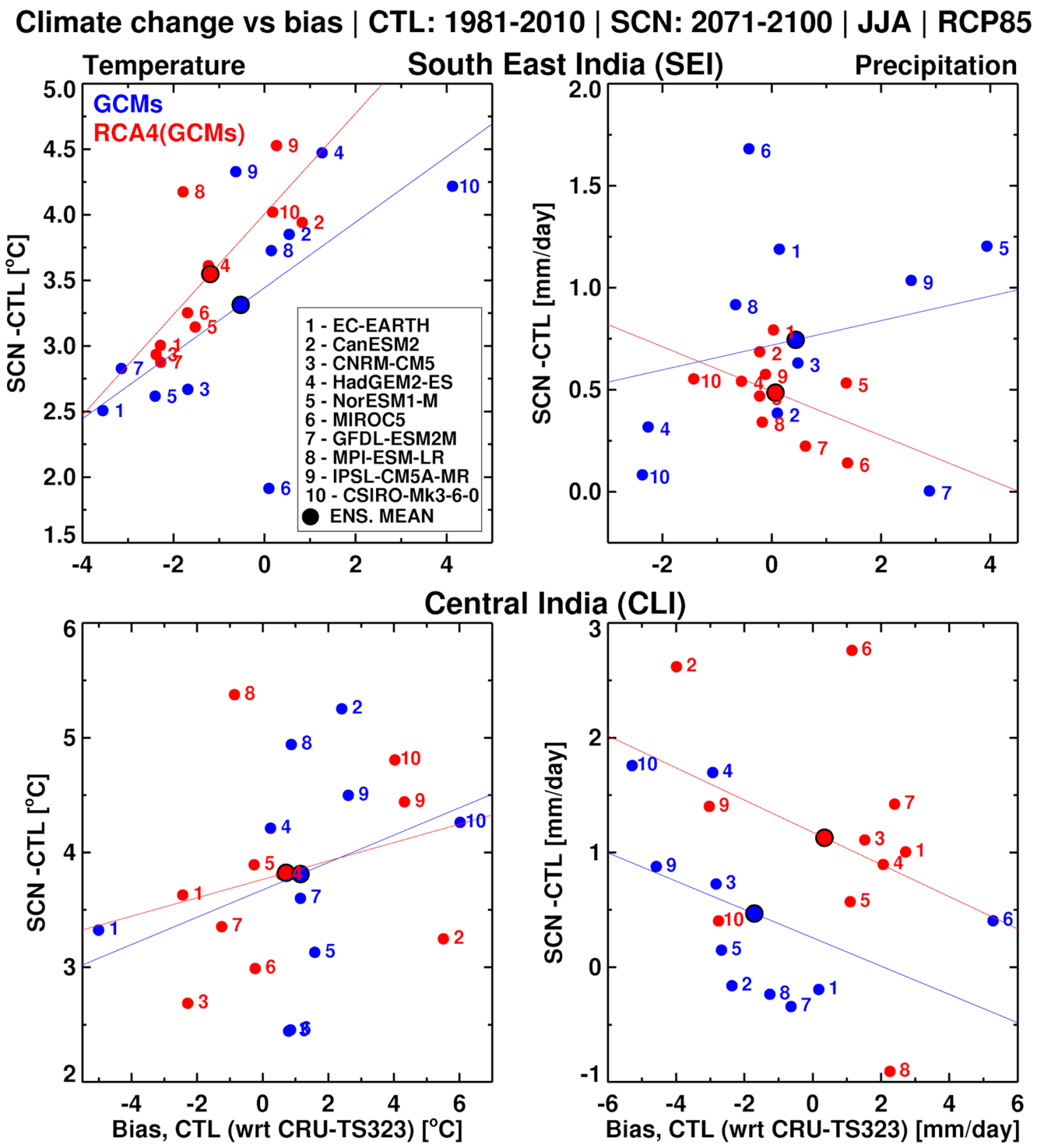

Fig. 13 Projected changes in temperature and precipitation in the scenario period (2071-2100) as a function of biases in the control period (CTL: 1981-2010, difference with respect to CRU-TS323). Tempera-

ture and precipitation are averaged over South East India (SEI, top) and Central India (CLI, bottom) for summer (JJA). GCMs are in blue and $\mathrm{RCA} 4(\mathrm{GCMs})$ are in red. Thin lines present a linear fit

relationship meaning that larger warm/wet biases lead to larger projected increases in temperature/precipitation.

\section{Conclusions}

In this study we analyse two ensembles of climate projections: one generated by $10 \mathrm{GCMs}$ and one by a RCM (SMHI-RCA4) downscaling the $10 \mathrm{GCMs}$ over the CORDEX South Asia domain at $50 \mathrm{~km}$ resolution. Our focus is on analysing differences and similarities between the two ensembles in seasonal mean temperature and precipitation during the Indian Summer Monsoon (June-August). Our results show that RCA4 performs better in some cases (e.g. reduction of the cold bias in EC-EARTH and warm bias in MIROC, GFDL and MPI-ESM). At the same time RCA4 performance is worse in other cases (e.g. an amplified cold bias in parts of the Himalayan region for most GCMs). For climate change we see that RCA4 can modify the signal projected by the GCM ensemble and its individual members. 
Table 4 The slope and onesigma uncertainty estimates for a linear fit to projected changes in temperature and precipitation ([2071-2100]-[1981-2020]) as a function of biases in 1981-2010 (difference with respect to CRU-TS232)

\begin{tabular}{|c|c|c|c|c|c|c|c|c|}
\hline \multirow[t]{3}{*}{ Region } & \multicolumn{4}{|c|}{ Temperature } & \multicolumn{4}{|c|}{ Precipitation } \\
\hline & \multicolumn{2}{|l|}{ RCA4 } & \multicolumn{2}{|l|}{ GCMs } & \multicolumn{2}{|l|}{ RCA4 } & \multicolumn{2}{|l|}{ GCMs } \\
\hline & Slope & Sigma & Slope & Sigma & Slope & Sigma & Slope & Sigma \\
\hline Central India & 0.08 & 0.1 & 0.12 & 0.12 & -0.14 & 0.14 & -0.12 & 0.08 \\
\hline South West India & 0.2 & 0.11 & 0.29 & 0.14 & 0.10 & 0.17 & 0.38 & 0.11 \\
\hline South East India & $\mathbf{0 . 3 8}$ & 0.11 & 0.25 & 0.11 & -0.11 & 0.07 & 0.06 & 0.09 \\
\hline North Pakistan and India & 0.42 & 0.16 & 0.08 & 0.13 & 0.07 & 0.27 & 0.16 & 0.12 \\
\hline South Pakistan and India & 0.48 & 0.18 & -0.02 & 0.13 & 0.15 & 0.20 & -0.02 & 0.11 \\
\hline Nepal & 0.32 & 0.1 & 0.06 & 0.1 & -0.23 & 0.17 & 0.08 & 0.1 \\
\hline Bangladesh & 0.21 & 0.11 & 0.03 & 0.18 & -0.26 & 0.24 & -0.12 & 0.17 \\
\hline Bhutan & 0.47 & 0.10 & 0.05 & 0.07 & 0.02 & 0.34 & 0.09 & 0.13 \\
\hline Myanmar & 0.35 & 0.16 & 0.24 & 0.23 & 0.04 & 0.38 & 0.23 & 0.12 \\
\hline
\end{tabular}

The slope statistically significant at the 0.05 significance level is in bold
For example, we note a substantial reduction of projected warming in a few RCA4 simulations compared to the driving GCMs. Another example relates to precipitation changes in Central India where RCA4 driven by two GCMs (MIROC and CanESM) projects a large increase absent in the GCMs. The results indicate that downscaling can change both the mean and spread as projected by the GCM ensemble. Particularly, downscaling reduces the spread in projected temperature increase in low-lying regions. For precipitation we identified regions with either larger (Central India) or smaller (South-East India) spread in the RCA4 ensemble compared to the GCM one. Additionally, we show that selecting a subset of GCMs from a grand ensemble can have a strong impact on projected regional climate change.

We also investigate how projected climate changes may depend on model biases in the historical period. For example, as shown by Boberg and Christensen (2012), warm biases may lead to stronger warming. Similarly, we found stronger warming in a number of regions where RCA4 has a warm bias. Also, we found a weaker warming when RCA4 has a cold bias. However, the GCM simulations do not show this kind of dependency. For precipitation there is no such relationship in either RCA4 or the GCMs.

We recognize that our study is descriptive but we argue that such an analysis of global and regional ensembles is a first necessary step in analysing drivers of regional climate change. For a deeper understanding of the drivers a more comprehensive analysis of relevant processes, processedbased evaluation, is required (e.g. James et al. 2018; Tamoffo et al. 2019).

Our results implicate that for impact and adaption studies there is a need for a careful evaluation and analysis of both GCM and RCM ensembles. Such kind of in depth analysis is essential for Climate Services based on global and regional climate models. Excluding GCMs and using only RCMs, a commonly established approach, can significantly change the message on future regional climate change.

Acknowledgements We acknowledge the World Climate Research Programme's Working Group on Regional Climate, and the Working Group on Coupled Modelling, former coordinating body of CORDEX and responsible panel for CMIP5. We also thank all climate modelling groups for producing and making available their model outputs. The US Department of Energy's Program for Climate Model Diagnosis and Intercomparison provides coordinating support and leads development of software infrastructure in partnership with the Global Organization for Earth System Science Portals. Further we would like to acknowledge the computing resources available at SMHI for the RCA4 model calculations.

Open Access This article is licensed under a Creative Commons Attribution 4.0 International License, which permits use, sharing, adaptation, distribution and reproduction in any medium or format, as long as you give appropriate credit to the original author(s) and the source, provide a link to the Creative Commons licence, and indicate if changes were made. The images or other third party material in this article are included in the article's Creative Commons licence, unless indicated otherwise in a credit line to the material. If material is not included in the article's Creative Commons licence and your intended use is not permitted by statutory regulation or exceeds the permitted use, you will need to obtain permission directly from the copyright holder. To view a copy of this licence, visit http://creativecommons.org/licenses/by/4.0/.

\section{References}

Abbas F, Ahmad A, Safeeq M et al (2014) Changes in precipitation extremes over arid to semiarid and subhumid Punjab, Pakistan. Theor Appl Climatol 116:671-680. https://doi.org/10.1007/s0070 4-013-0988-8

Amin A, Nasim W, Mubeen M et al (2018) Regional climate assessment of precipitation and temperature in Southern Punjab (Pakistan) using SimCLIM climate model for different temporal scales. Theor Appl Climatol 131:121-131. https://doi.org/10.1007/s0070 4-016-1960-1 
Boberg F, Christensen JH (2012) Overestimation of Mediterranean summer temperature projections due to model deficiencies. Nat Clim Change 2:433-436. https://doi.org/10.1038/nclimate1454

Collins M, Knutti R, Arblaster J et al (2013) Long-term climate change: projections, commitments and irreversibility. In: Climate change 2013 the physical science basis: Working Group I contribution to the fifth assessment report of the intergovernmental panel on climate change. pp 1029-1136

Corrales-Suastegui A, Fuentes-Franco R, Pavia EG (2019) The midsummer drought over Mexico and Central America in the 21st century. Int J Climatol. https://doi.org/10.1002/joc.6296

Dash SK, Mishra SK, Pattnayak KC et al (2015) Projected seasonal mean summer monsoon over India and adjoining regions for the twenty-first century. Theor Appl Climatol 122:581-593. https:// doi.org/10.1007/s00704-014-1310-0

Dastagir MR (2015) Modeling recent climate change induced extreme events in Bangladesh: a review. Weather Clim Extrem 7:49-60. https://doi.org/10.1016/j.wace.2014.10.003

Dee DP, Uppala SM, Simmons AJ et al (2011) The ERA-Interim reanalysis: configuration and performance of the data assimilation system. Q J R Meteorol Soc 137:553-597. https://doi.org/10.1002/ qj. 828

Di Luca A, de Elía R, Laprise R (2015) Challenges in the quest for added value of regional climate dynamical downscaling. Curr Clim Change Rep 1:10-21. https://doi.org/10.1007/s4064 1-015-0003-9

Feron S, Cordero RR, Damiani A et al (2019) Observations and projections of heat waves in South America. Sci Rep 9:8173. https://doi. org/10.1038/s41598-019-44614-4

Ghimire S, Choudhary A, Dimri AP (2018) Assessment of the performance of CORDEX-South Asia experiments for monsoonal precipitation over the Himalayan region during present climate: part I. Clim Dyn 50:2311-2334. https://doi.org/10.1007/s0038 2-015-2747-2

Giorgi F, Mearns LO (1991) Approaches to the simulation of regional climate change: a review. Rev Geophys 29:191. https://doi. org/10.1029/90RG02636

Giorgi F, Jones C, Asrar GR (2009) Addressing climate information needs at the regional level: the CORDEX framework. World Meteorol Organ Bull 58(3):175-183

Guhathakurta P, Rajeevan M (2008) Trends in the rainfall pattern over India. Int J Climatol 28:1453-1469. https://doi.org/10.1002/ joc. 1640

Harris I, Jones PD, Osborn TJ, Lister DH (2014) Updated high-resolution grids of monthly climatic observations-the CRU TS3.10 Dataset. Int J Climatol 34:623-642. https://doi.org/10.1002/ joc. 3711

Hassan M, Du P, Jia S et al (2015) An assessment of the South Asian summer monsoon variability for present and future climatologies using a high resolution regional climate model (RegCM4.3) under the AR5 scenarios. Atmosphere (Basel) 6:1833-1857. https://doi. org/10.3390/atmos6111833

Hazeleger W, Wang X, Severijns C et al (2012) EC-Earth V2.2: description and validation of a new seamless earth system prediction model. Clim Dyn 39:2611-2629. https://doi. org/10.1007/s00382-011-1228-5

Hijioka Y, Lin E, Pereira JJ et al (2014) Asia. In: Barros VR, Field CB, Dokken DJ et al (eds) Climate change 2014: impacts, adaptation, and vulnerability. Part B: regional aspects. Contribution of working group II to the fifth assessment report of the intergovernmental panel of climate change. Cambridge University Press, Cambridge, pp 1327-1370

James R, Washington R, Abiodun B et al (2018) Evaluating climate models with an African lens. Bull Am Meteorol Soc 99:313336. https://doi.org/10.1175/BAMS-D-16-0090.1
Jones C, Giorgi F, Asrar G (2011) The coordinated regional downscaling experiment: CORDEX, an international downscaling link to CMIP5. Clivar Exch 16:34-39

Karmacharya J, Jones R, Moufouma-Okia W, New M (2017) Evaluation of the added value of a high-resolution regional climate model simulation of the South Asian summer monsoon climatology. Int J Climatol 37:3630-3643. https://doi.org/10.1002/ joc. 4944

Kjellström E, Bärring L, Nikulin G et al (2016) Production and use of regional climate model projections-a Swedish perspective on building climate services. Clim Serv 2-3:15-29. https://doi. org/10.1016/j.cliser.2016.06.004

Kothawale D, Munot A, Krishna Kumar K (2010) Surface air temperature variability over India during 1901-2007, and its association with ENSO. Clim Res 42:89-104. https://doi.org/10.3354/ cr00857

Krishnamurti V, Shukla J (2000) Intraseasonal and interannual variability of rainfall over India. J Clim 13:4366-4377. https://doi. org/10.1175/1520-0442(2000)013\%3c0001:IAIVOR\%3e2.0.CO;2

Krishnaswamy J, Vaidyanathan S, Rajagopalan B et al (2015) Non-stationary and non-linear influence of ENSO and Indian Ocean Dipole on the variability of Indian monsoon rainfall and extreme rain events. Clim Dyn 45:175-184. https://doi. org/10.1007/s00382-014-2288-0

Kulkarni MA, Singh A, Mohanty UC (2012) Effect of spatial correlation on regional trends in rain events over India. Theor Appl Climatol 109:497-505. https://doi.org/10.1007/s00704-012-0602-5

Legates DR, Willmott CJ (1990) Mean seasonal and spatial variability in gauge-corrected, global precipitation. Int J Climatol 10:111-127. https://doi.org/10.1002/joc.3370100202

Llopart M, Simões Reboita M, Porfírio da Rocha R (2020) Assessment of multi-model climate projections of water resources over South America CORDEX domain. Clim Dyn 54:99-116. https ://doi.org/10.1007/s00382-019-04990-z

Maharana P, Dimri AP (2016) Study of intraseasonal variability of Indian summer monsoon using a regional climate model. Clim Dyn 46:1043-1064. https://doi.org/10.1007/s00382-015-2631-0

Menon A, Levermann A, Schewe J et al (2013) Consistent increase in Indian monsoon rainfall and its variability across CMIP-5 models. Earth Syst Dyn 4:287-300. https://doi.org/10.5194/ esd-4-287-2013

Mishra V (2015) Climatic uncertainty in Himalayan water towers. J Geophys Res Atmos 120:2689-2705. https://doi. org/10.1002/2014JD022650

Mishra V, Kumar D, Ganguly AR et al (2014) Reliability of regional and global climate models to simulate precipitation extremes over India. J Geophys Res Atmos 119:9301-9323. https://doi. org/10.1002/2014JD021636

Mishra V, Ganguly AR, Nijssen B, Lettenmaier DP (2015) Changes in observed climate extremes in global urban areas. Environ Res Lett 10:024005. https://doi.org/10.1088/1748-9326/10/2/024005

Moss RH, Edmonds JA, Hibbard KA et al (2010) The next generation of scenarios for climate change research and assessment. Nature 463:747-756. https://doi.org/10.1038/nature08823

Nikulin G, Jones C, Giorgi F, Asrar G, Büchner M, Cerezo-Mota R, Christensen OB, Déqué M, Fernandez J, Hänsler A, van Meijgaard E (2012) Precipitation climatology in an ensemble of CORDEXAfrica regional climate simulations. J Clim 25(18):6057-6078

Nikulin G, Lennard C, Dosio A, Kjellström E, Chen Y, Hänsler A, Kupiainen M, Laprise R, Mariotti L, Maule CF, van Meijgaard E (2019) The effects of $15^{\circ}$ and $2^{\circ}$ of global warming on Africa in the CORDEX ensemble. Environ Res Lett 13(6):065003

Pai DS, Nair SA, Ramanathan AN (2013) Long term climatology and trends of heat waves over India during the recent 50 years (19612010). Mausam 64(4):585-604 
Revadekar JV, Kothawale DR, Patwardhan SK et al (2012) About the observed and future changes in temperature extremes over India. Nat Hazards 60:1133-1155. https://doi.org/10.1007/s1106 9-011-9895-4

Rockel B (2015) The regional downscaling approach: a brief history and recent advances. Curr Clim Change Rep 1:22-29. https://doi. org/10.1007/s40641-014-0001-3

Roxy MK, Ritika K, Terray P et al (2015) Drying of Indian subcontinent by rapid Indian Ocean warming and a weakening land-sea thermal gradient. Nat Commun 6:7423. https://doi.org/10.1038/ ncomms 8423

Rummukainen M (2016) Added value in regional climate modeling. Wiley Interdiscip Rev Clim Change 7:145-159. https://doi. org/10.1002/wcc.378

Sabeerali CT, Rao SA, Dhakate AR et al (2015) Why ensemble mean projection of south Asian monsoon rainfall by CMIP5 models is not reliable? Clim Dyn 45:161-174. https://doi.org/10.1007/ s00382-014-2269-3

Sajjad S, Yiming L, Rasul G (2011) Multiyear hindcast simulations of summer monsoon over South Asia using a nested regional climate model-BCC_RegCM1.0. Theor Appl Climatol 103:249-264. https://doi.org/10.1007/s00704-010-0297-4

Samuelsson P, Gollvik S, Jansson C, Kupiainen M, Kourzeneva E, van de Berg WJ (2015) The surface processes of the Rossby Centre regional atmospheric climate model (RCA4). Meteorologi 157. Swedish Meteorological and Hydrological Institute (SMHI)

Schneider U, Becker A, Finger P et al (2014) GPCC's new land surface precipitation climatology based on quality-controlled in situ data and its role in quantifying the global water cycle. Theor Appl Climatol 115:15-40. https://doi.org/10.1007/s00704-013-0860-x

Shahid S, Wang X-J, Harun SB et al (2016) Climate variability and changes in the major cities of Bangladesh: observations, possible impacts and adaptation. Reg Environ Change 16:459-471. https ://doi.org/10.1007/s10113-015-0757-6

Singh S, Ghosh S, Sahana AS et al (2017) Do dynamic regional models add value to the global model projections of Indian monsoon? Clim Dyn 48:1375-1397. https://doi.org/10.1007/s0038 2-016-3147-y

Sørland SL, Schär C, Lüthi D, Kjellström E (2018) Bias patterns and climate change signals in GCM-RCM model chains. Environ Res Lett 13:074017. https://doi.org/10.1088/1748-9326/aacc77

Strandberg G, Bärring L, Hansson U et al (2014) CORDEX scenarios for Europe from the Rossby Centre regional climate model RCA4. Rep Meteorol Climatol 116:84

Tamoffo AT, Moufouma-Okia W, Dosio A et al (2019) Process-oriented assessment of RCA4 regional climate model projections over the Congo Basin under $1.5{ }^{\circ} \mathrm{C}$ and $2{ }^{\circ} \mathrm{C}$ global warming levels: influence of regional moisture fluxes. Clim Dyn 53:1-25. https://doi.org/10.1007/s00382-019-04751-y

Teichmann C, Eggert B, Elizalde A et al (2013) How does a regional climate model modify the projected climate change signal of the driving GCM: a study over different CORDEX regions using REMO. Atmosphere (Basel) 4:214-236. https://doi.org/10.3390/ atmos 4020214

Varikoden H, Mujumdar M, Revadekar JV et al (2018) Assessment of regional downscaling simulations for long term mean, excess and deficit Indian Summer Monsoons. Glob Planet Change 162:28-38. https://doi.org/10.1016/j.gloplacha.2017.12.002

Publisher's Note Springer Nature remains neutral with regard to jurisdictional claims in published maps and institutional affiliations. 